\title{
Numerical investigation for optimizing segmented micro-channel heat sink by Taguchi-Grey method
}

Nor Haziq Naqiuddin ${ }^{\mathrm{a}}$, Lip Huat Saw ${ }^{\mathrm{a} *}$, Ming Chian Yew ${ }^{\mathrm{a}}$, Farazila Yusof ${ }^{\mathrm{b}}$, Hiew Mun Poon $^{\mathrm{a}}$, Zuansi Cai ${ }^{\mathrm{c}}$, Hui San Thiam ${ }^{\mathrm{a}}$

${ }^{\text {a }}$ Lee Kong Chian Faculty of Engineering and Science, UTAR, Kajang, Malaysia 43000.

${ }^{\mathrm{b}}$ Department of Mechanical Engineering, Faculty of Engineering, University of Malaya, Malaysia - 50603.

c School of Engineering and The Built Environment, Edinburgh Napier University, Edinburgh EH10 5DT, UK.

* Corresponding author

Phone: $+603-90860288$

Fax: $\quad+603-90193886$

E-mail address: sawlh@utar.edu.my; bernardsaw81@yahoo.com

\section{Abstract}

The scale-down trend increases the chips’ density and the high power handling capability generates unnecessary heat which can disrupt the reliability of the electronic devices. Therefore, various types of cooling solution have been proposed to enhance heat dissipation from the electronic devices. One of the solution is using inexpensive straightchannel heat sink. However, the presence of large temperature gradient between the upstream and downstream in the straight-channel can shorten the life span of the device and subsequently reduce the reliability. In this study, a novel segmented micro-channel is introduced to improve the thermal performance of the straight-channel heat sink. Computational fluid dynamic analysis are performed to investigate the performance of the micro-channel heat sink. The bottom of the heat sink is subjected to a constant heat flux condition and water is used as a coolant. Following that, Taguchi-grey method is applied to optimize the design of the segmented micro-channel. The effect of fin width, fin length, fin transverse distance, number of segments, channel width and mass flow rate 
on the specific performance, variation of temperature and pressure drop are investigated. The results indicate that a three segments of segmented micro-channel, fin width- $1 \mathrm{~mm}$, fin length-2 mm, fin transverse distance- $5 \mathrm{~mm}$ and channel width-1 mm have successfully enhance the heat transfer performance with minimum pressure drop. It is also found that the optimized micro-channel heat sink is able to cool the chip with heat flux of $800 \mathrm{~W}$ to $56.6{ }^{\circ} \mathrm{C}$ and pumping power of $0.13 \mathrm{~W}$ using $15 \mathrm{gs}^{-1}$ of water.

Keywords: micro-channel; heat sink; thermal management; segmented micro-channel; computational fluid dynamics 


\section{Introduction}

Rapid development of the IT industry has caused tremendous increment in the heat generation of the IC chips while air cooling technology has reached its limit. The most challenging issues faced by the industry in designing an electronic devices is to overcome the heat dissipation issue caused by scaling down the size of the device while increasing the power handling capability as well as the chip density [1]. The statistics from the International Technology Roadmap for Semiconductor (ITRS) indicate that, the power density generated by an electronic device could reach $100 \mathrm{Wcm}^{-2}$ by 2020 [2]. On the other hand, the heat load could even reach $1000 \mathrm{Wcm}^{-2}$ using intensive heat generation devices such as laser weapon and radar. Therefore, thermal management technology using micro-channel heat sinks has gained a great extent of popularity due to its superior heat removal capabilities through small-scale surface area in comparison to the conventional heat sink [3]. In view of this, the use of micro-channel heat sink can be found in a wide range of applications, such as military and defence, bio-engineering, medical, nuclear industry, solar cell, fuel cell and electronic devices [4].

Micro-channel heat sink was initially introduced by Tuckerman and Pease to improve the heat transfer performance of a conventional macro-channel heat sink [6]. It was found that the thermal resistance of the cooling target is reduced by increasing the aspect ratio of the channel to surface area and it is able to dissipate a maximum heat load of $790 \mathrm{Wcm}^{-}$ ${ }^{2}$. Additionally, the heat transfer performance is improved with the use of micro-channel as a result of the increased surface area to volume ratio. As a consequence, it can support greater packaging density in the future without worrying the heat generation issue $[1,6]$. Furthermore, Balasubramanian et al. have conducted an experimental study on a straight and expanding micro-channel heat sink with similar dimensions and operating conditions [7]. The micro-channel is made from a copper block with dimensions of $25 \mathrm{~mm}$ (length) 
$\times 25 \mathrm{~mm}$ (width) and channel width is about $300 \mu \mathrm{m}$. From the experiment, it is observed that the expanding micro-channel heat sink is able to provide better stabilizing effect as compared to the straight-channel heat sink. The pressure drop across the expanding micro-channel is $30 \%$ less than the straight-channel with lower pumping power to dissipate the same amount of heat flux. Although the expanding micro-channel heat sink has a lower convective heat transfer area, the thermal performance is relatively higher than that of the straight-channel heat sink. On the hand, a wavy micro-channel has been introduced by Lin et al. to further improve the heat dissipation performance of the heat sink by varying the wavelength and the amplitude of the wavy micro-channel [8]. As the wavelength or amplitude increases, the thermal resistance and variation of temperature of the cooling target is reduced. On top of that, flow disruption in a wavy channel promotes vortex creation which aids in coolant mixing and subsequently enhances the microchannel heat sink performance. Besides, Chai et al. have conducted a series of numerical analysis to investigate the flow and heat transfer characteristics of an interrupted microchannel heat sink by installing different configurations of ribs in the transverse microchambers [9]. Based on the simulation results obtained, it is demonstrated that the heat transfer performance of an interrupted micro-channel heat sink is comparatively greater than that of a straight- channel heat sink owing to the enhanced heat transfer coefficient through fluid mixing and re-initialization of the thermal boundary layer in the microchannel heat sink. Besides, Pan et al. have investigated methanol stream reforming in the micro-channel reactors [10]. There are two different types of micro-channel cross section, namely rectangular and tooth micro-channel, and four kinds of micro-channel distributions used in the study. The experimental results show that micro-channel distribution is the major dominant on the reaction performance of methanol steam reforming. Law et al. to analyse the heat transfer performance of the straight-channel and 
oblique-finned micro-channel heat sinks [11]. A $25 \mathrm{~mm}$ x $25 \mathrm{~mm}$ copper block is used to fabricate parallel micro-channels and oblique cuts of angle $27^{\circ}$ was introduced by half of the parallel channel width. The application of oblique-finned micro-channel has successfully improved the heat transfer performance of the heat sink by 6.2 times as compared to the straight-channel. This can be attributed to the higher amount of bubbles generated in the nucleate boiling regime as well as the development of thin liquid-film in the convective boiling regime. In addition, oblique-finned micro-channel also offers more stable flow boiling process as compared to the straight-channel.

On the other hand, it is noted that one of the major drawbacks of straight-channel design in micro-channel heat sink is the decreased cooling efficiency along channel flow path, which subsequently leads to large temperature difference between upstream and downstream of the heated surface. To counter this problem, secondary flow can be introduced in the channel to improve the fluid mixing process and to disrupt the thermal boundary development [12]. In view of this, Jin et al. have used the concept of oblique fin mini-channel and fabricated it into liquid cold plate to examine the flow field and heat transfer characteristics numerically and experimentally [12]. As the secondary flow intensifies, the heat transfer is increased and simultaneously a pressure drop is observed. Furthermore, nanofluids can be circulated through the micro/mini-channel to enhance the thermal performance [13]. It is found that, the overall thermal performance of the microchannel heat sink using nanofluids is improved drastically compared to pure liquid coolant.

In order to increase the heat transfer and reduce the pressure drop in the microchannel heat sink, several optimization techniques have been used to improve the heat sink designs [14]. Sahin et al. have applied Taguchi method to improve the convergence and divergence heat sink [15]. ANOVA is used to optimize the heat transfer and pressure 
drop characteristic of the heat sink by considering the contribution ratio of individual design parameters. It is found that fin height, fluid velocity and stream-wise distance between fins are the parameters affecting the heat transfer performance. On the other hand, angle of attack is the most important parameter which causes the pressure drop in the heat sink. On the other hand, Chen et al. have optimized the efficiency of the thermoelectric generator using Taguchi method [16]. The orthogonal array of $\mathrm{L}_{25}\left(5^{6}\right)$ with six design parameters namely external load resistance, hot side temperature, thickness and height of fins as well as length and width of the heat sink is used in the optimization process. It is found that the power output of the thermoelectric electric system has been successfully improved by $6 \%$. Moreover, Taguchi method is also utilized to optimize the ground heat exchangers for cooling and heating applications [17]. The orthogonal array $\mathrm{L}_{27}\left(3^{8}\right)$ is used to optimize the minimum length required for a ground heat exchanger. The optimization results demonstrate that thermal conductivity and pipe diameter are the key parameters for improving heat transfer performance in the vertical and horizontal ground heat exchanger. Besides, Srikanth et al. have performed multi-objective geometric optimization to minimize the cooling time and maximize the heating time of the phase change material (PCM) based heat sink using non sorted genetic algorithm (NSGA II) [18]. Operation time of the PCM heat sink during charging cycle can be stretched by $5 \%$ via the optimization process and discharging cycle can be reduced by $12.5 \%$. Jang et al. have also optimized the heat transfer performance of the pin-fin radial heat sink using multi-objective optimization [19]. The cooling performance of the pin-fin radial heat sink is successfully improved by $45 \%$ as compared to that of plate-fin heat sink. Additionally, fin height is found to be an important factor that influences the cooling performance of the radial heat sink. 
In order to overcome the challenges in dissipating high heat load and to satisfy the stringent requirements of the operating temperature in the electronic devices, the objective of this work focuses on the design and development of the novel segmented micro-channel heat sink. First of all, a CFD model is developed to predict the flow and heat transfer characteristics of a novel segmented micro-channel heat sinks for various design parameters such as fin width, fin length, fin transverse distance, channel width, number of segments and mass flow rate. Next, Taguchi-Grey optimization technique is used to optimize the geometrical design with different design parameters to predict the best combination which can produce maximum heat transfer with minimum pressure loss and temperature variation. In addition, the simulation results of the straight-channel heat sink are compared with the validated experimental results from the literature. The comparison are useful to provide fundamental understanding of the heat transfer performance and flow field of the segmented micro-channel heat sink compared to conventional straight-channel heat sink. The rest of the paper is organized as followings, Section 2 explains the design of the micro-channel, numerical modelling procedure and also Taguchi-Grey optimization procedure used to determine the best combination of design parameters for the novel segmented micro-channel heat sink. Section 3, discusses the optimization results and compares the flow and heat transfer performance of the novel segmented micro-channel with those of the straight-channel. Besides, comparison of simulation results for straight-channel with correlations from literature is also presented. Finally, Section 4 summarizes the findings of the current study and conclusions are drawn. 


\begin{tabular}{|c|c|}
\hline \multicolumn{2}{|c|}{ Nomenclature } \\
\hline$A_{c}$ & Free flow area, $\mathrm{m}^{2}$ \\
\hline$A_{f}$ & Total convective heat transfer area in contact with the fluid, $\mathrm{m}^{2}$ \\
\hline$A_{s}$ & Total heat transfer area, $\mathrm{m}^{2}$ \\
\hline$C_{p}$ & Specific heat capacity, $\mathrm{J} \mathrm{kg}^{-1} \cdot \mathrm{K}^{-1}$ \\
\hline$D_{h}$ & Hydraulic diameter, $\mathrm{m}$ \\
\hline$f$ & Friction factor \\
\hline$G$ & Mass flux of water based on minimum flow area, $\left(\frac{\dot{m}}{A_{A}}\right) \mathrm{kg} \cdot \mathrm{m}^{-2} \mathrm{~s}^{-1}$ \\
\hline $\bar{h}$ & Convection heat transfer coefficient, W. $\mathrm{m}^{-2} \cdot \mathrm{K}^{-1}$ \\
\hline$L$ & Length of the heat sink \\
\hline$k$ & Thermal conductivity, $\mathrm{W} \cdot \mathrm{m}^{-1} \cdot \mathrm{K}^{-1}$ \\
\hline$\dot{m}$ & Mass flow rate of water, kg.s ${ }^{-1}$ \\
\hline $\max x_{0}^{i}(k)$ & Maximum value of $x_{i}^{0}(k)$ for the $k^{\text {th }}$ response \\
\hline $\min x_{0}^{i}(k)$ & Minimum value of $x_{i}^{0}(k)$ for the $k^{\text {th }}$ response \\
\hline $\mathrm{n}$ & Number of simulation run \\
\hline $\mathrm{Nu}$ & Nusselt number \\
\hline$p$ & Pressure, $\mathrm{Pa}$ \\
\hline $\mathrm{PD}$ & Pressure drop \\
\hline$\dot{Q}$ & Amount of heat generated, W \\
\hline$\dot{Q}_{\text {conv }}$ & Amount of heat dissipated through convection, $\mathrm{W}$ \\
\hline$\dot{Q}_{\text {rad }}$ & Amount of heat dissipated through radiation, W \\
\hline$\dot{Q}_{\text {loss }}$ & Amount of heat loss due to poor insulation, W \\
\hline $\operatorname{Re}$ & Reynolds number \\
\hline$r_{h}$ & Hydraulic radius, m \\
\hline SP & Specific performance \\
\hline $\bar{T}_{s}$ & Average surface temperature, $\mathrm{K}$ \\
\hline $\mathrm{T}$ & Temperature, $\mathrm{K}$ \\
\hline TV & Temperature variation \\
\hline$u$ & Velocity, m/s \\
\hline$U_{\infty}$ & Inlet velocity of water, $\mathrm{m} \cdot \mathrm{s}^{-1}$ \\
\hline$V$ & Volume of the heat sink, $\mathrm{m}^{3}$ \\
\hline$\dot{V}$ & Volumetric flow rate, $\mathrm{m}^{3} \mathrm{~s}^{-1}$ \\
\hline$V_{f}$ & Total fluid volume inside the heat sink, $\mathrm{m}^{3}$ \\
\hline$w_{k}$ & Normalized weight value of $k^{\text {th }}$ performance characteristic \\
\hline$W_{p p}$ & Pumping power, $\mathrm{W}$ \\
\hline$x_{i}^{0}(k)$ & Normalized value of the $k^{\text {th }}$ element in the $i^{\text {th }}$ sequence. \\
\hline$x_{i}(k)$ & Value after the grey relational generation \\
\hline$x_{0}^{*}(k)$ & Referential sequence \\
\hline$x_{i}^{*}(k)$ & Comparative sequence \\
\hline$Y_{i}$ & Performance value of the simulation $\mathrm{i}^{\text {th }}$ \\
\hline$\Delta_{\min }$ & Smallest value of $\Delta_{0 i}, 0$ \\
\hline$\Delta_{\max }$ & Largest value of $\Delta_{0 i}, 1$ \\
\hline$\Delta p$ & Pressure drop through heat sink, $\mathrm{Pa}$ \\
\hline$\Delta \theta$ & Change of temperature, $\mathrm{K}$ \\
\hline$\Delta \Delta_{0 i}$ & $\begin{array}{l}\text { deviation sequence between reference sequence and the comparable } \\
\text { sequence with } x_{0}^{*}(k)=1\end{array}$ \\
\hline
\end{tabular}




\begin{tabular}{|ll|}
\hline \multicolumn{2}{|l|}{ Greek symbol } \\
$\eta$ & Signal to noise ratio \\
$\rho$ & Density, kg.m ${ }^{-3}$ \\
$\mu$ & Dynamic viscosity, $\mathrm{kg}_{\mathrm{m}} \mathrm{m}^{-1} \cdot \mathrm{s}^{-1}$ \\
$\gamma_{i}$ & Overall grey relational grade for $i^{\text {th }}$ experiment \\
$\psi$ & Distinguishing or identification coefficient \\
& \\
Subscripts & \\
in & Inlet \\
max & Maximum \\
out & Outlet \\
\hline
\end{tabular}

\section{Design and analysis of the micro-channel heat sink}

\subsection{Micro-channel heat sink design}

There are two different types of micro-channel heat sink used in the current study namely straight-channel and segmented micro-channel heat sink. The CAD model of the heat sinks is developed using Solidworks 2016. Following that, a commercial computational fluid dynamics software, namely ANSYS CFX is employed to examine the heat transfer and flow characteristics in the micro-channel heat sinks. The foot print of the micro-channel heat sinks is $30 \mathrm{~mm}$ (width) x $30 \mathrm{~mm}$ (length), whereas the flow channel of the straight-channel heat sink is $1 \mathrm{~mm}$ (width) x $2 \mathrm{~mm}$ (depth). On the other hand, six design parameters are applied to optimize the segmented micro-channel heat sink including fin width, fin length, fin transverse distance, number of segments, channel width and mass flow rate. The designs of the straight-channel and segmented micro-channel heat sinks are depicted in Fig. 1.

\subsection{Computational fluid dynamic analysis}

In this section, a three dimensional conjugate heat transfer model is used to investigate the flow field and thermal performance of the micro-channel heat sinks. Several assumptions are made in this simulation: (a) constant thermophysical properties, (b) no energy source present in the fluid, (c) steady state flow condition, (d) incompressible flow, (e) no gravity effect and (f) the test rig was well insulated with no heat loss. In order 
to solve the conjugate heat transfer problem, continuity, momentum and energy equations as following are used [20-22].

Continuity equation:

$\frac{\partial u_{x}}{\partial x}+\frac{\partial u_{y}}{\partial y}+\frac{\partial u_{z}}{\partial z}=0$

$X$-momentum equation:

$\rho\left(u_{x} \frac{\partial u_{x}}{\partial x}+u_{y} \frac{\partial u_{x}}{\partial y}+u_{z} \frac{\partial u_{x}}{\partial z}\right)=-\frac{\partial p}{\partial x}+\mu \cdot\left(\frac{\partial^{2} u_{x}}{\partial x^{2}}+\frac{\partial^{2} u_{x}}{\partial y^{2}}+\frac{\partial^{2} u_{x}}{\partial z^{2}}\right)$

Y-momentum equation:

$\rho\left(u_{x} \frac{\partial u_{y}}{\partial x}+u_{y} \frac{\partial u_{y}}{\partial y}+u_{z} \frac{\partial u_{y}}{\partial z}\right)=-\frac{\partial p}{\partial y}+\mu \cdot\left(\frac{\partial^{2} u_{y}}{\partial x^{2}}+\frac{\partial^{2} u_{y}}{\partial y^{2}}+\frac{\partial^{2} u_{y}}{\partial z^{2}}\right)$

Z-momentum equation:

$\rho\left(u_{x} \frac{\partial u_{z}}{\partial x}+u_{y} \frac{\partial u_{z}}{\partial y}+u_{z} \frac{\partial u_{z}}{\partial z}\right)=-\frac{\partial p}{\partial z}+\mu \cdot\left(\frac{\partial^{2} u_{z}}{\partial x^{2}}+\frac{\partial^{2} u_{z}}{\partial y^{2}}+\frac{\partial^{2} u_{z}}{\partial z^{2}}\right)$

According to the first law of thermodynamics, amount of heat rate added to the fluid domain and also the work done is equal to the energy changed in the fluid domain [2022]. Thus, the energy equation can be described as in Eq. 5:

Energy equation:

$\rho c_{f}\left(u_{x} \frac{\partial T}{\partial x}+u_{y} \frac{\partial T}{\partial y}+u_{z} \frac{\partial T}{\partial z}\right)=k_{f} \cdot\left(\frac{\partial^{2} T}{\partial x^{2}}+\frac{\partial^{2} T}{\partial y^{2}}+\frac{\partial^{2} T}{\partial z^{2}}\right)$

Where $\rho$ is the density of the fluid, $u$ is the mean velocity, $T$ is the temperature, $k$ is the thermal conductivity of the fluid, $p$ is the pressure of the fluid and $\mu$ is the viscosity of the fluid.

In order to appropriately apply the turbulence model in the CFD analysis, it is necessary to ensure that the flow is turbulent based on the computed Reynolds number (Re). In this study, the Reynolds number ranges from 3370 to 11236 for straight-channel heat sink and ranges from 260 to 2080 for segmented micro-channel heat sink. According to Fan et al. [23], the flow regimes in the segmented micro-channel heat sink or straight- 
channel heat sink are unstable and chaotic and the application of turbulence model will affect the accuracy of the heat transfer simulations. In addition, it is noted that no single turbulence model is accepted universally for all classes of industrial application and the results has not been verified and validated [24]. The turbulence model only yields accurate predictions in wall-bounded flows or free-shear flows but not both of them. Recently, SST turbulence model with automatic wall function has become the center of attention in the CFD analysis. Menter et al. and Vieser et al. have concluded that SST turbulence model is capable to produce high accuracy results over a wide range of heat transfer cases and the model has been proven for its capability in predicting the flow separation under adverse pressure gradients precisely by adding transport effects into the formulation of eddy-viscosity [25-27]. The SST turbulence model is similar to $\mathrm{k}-\varepsilon$ turbulence model for free shear flows and it can overcome deficiencies in the $k-\omega$ and BSL k- $\omega$ turbulence model. Nonetheless, SST turbulence model has its advantages in the low Reynolds number computations. The SST turbulence model will give a better prediction for laminar to turbulent flow and also near wall boundary conditions as well as wall shear and heat transfer behaviour [20]. The performance of the SST turbulence model has been validated by a large number of case studies [27]. The details of the SST turbulence model can be found in the following studies conducted by Menter et al., 2003, Sparrow et al. 2009 and Lee et al, 2013 [25, 28-29]. Therefore, SST turbulence model is selected for current study [20, 23-24, 30].

Hybrid meshing technique is used to discretize the straight-channel and segmented micro-channel domain into 2,376,444 and 6,495,016 elements using ANSYS ICEM CFD 17.2. Water is used as a cooling fluid and mass flow boundary condition is assigned to the inlet. Physical properties of the water and copper block used in the CFD simulation are tabulated in Table 1 . The inlet temperature of the water is kept at $30{ }^{\circ} \mathrm{C}$. On top of 
that, pressure boundary condition is assigned to the outlet. Uniform heat generation of $800 \mathrm{~W}$ is applied to the heater located at the bottom surface of the micro-channel heat sink. Contact resistance present between the heater and micro-channel heat sink is not modelled in this study. The confining walls on the micro-channel test rig are specified as non-slip and adiabatic wall boundary conditions. The computational domain is initialized with 1 atm pressure condition. Boundary details and setting used for the micro-channel heat sink are tabulated in Table 2. Simulation is executed with a high resolution scheme and first order turbulence numeric. The convergence criteria for continuity, momentum and energy (H-energy and T-energy) are set to $1.0 \times 10^{-6}$. Workstation with Intel i76800K, 3.4 GHz CPU and 64 GB DDR4 RAM is used to perform the simulation and the total computational time is about 8 hours.

\subsection{Grid Independent test}

Grid independent test is first conducted to ensure that the mesh of the micro-channel heat sink is appropriate to provide a reliable result for heat transfer and flow characterization. Here, the percentage of deviation of the analysis results must be less than $5 \%$ in order to ensure that the results are not affected by further mesh refinement. In the present study, five different mesh configurations, namely mesh-1 (coarse), mesh-2 (medium), mesh-3 (fine), mesh-4 (finer) and mesh-5 (finest) are used to assess the grid quality on the accuracy of the simulation results. The test results are summarized in Table 3. The grid independent test is conducted using mass flow rate of 20 gs $^{-1}$. Mesh-1, mesh2, mesh-3, mesh-4 and mesh-5 with 604,126, 1,302,955, 2,376,444, 4,227,917 and 8,539,682 elements, respectively are generated to model the straight-channel heat sink. On the other hand, mesh-1, mesh-2, mesh-3, mesh-4 and mesh-5 with 2,331,419, $4,389,590,6,495,016,12,069,880$ and 28,963,841 elements, respectively are generated to model the segmented micro-channel heat sink. From Table 3, it is clearly shown that the 
average temperature and pressure drop for the straight-channel are almost constant for five different mesh systems. The variation in average temperature for straight-channel is about $2.07 \%$ from mesh-1 to mesh-2, $0.03 \%$ from mesh-2 to mesh-3, $0.10 \%$ from mesh3 to mesh- 4 and $0.12 \%$ from mesh- 4 to mesh-5. Furthermore, the variation in the pressure drop for straight-channel is about $5.87 \%$ from mesh-1 to mesh-2, $1.79 \%$ from mesh-2 to mesh-3, $1.78 \%$ from mesh-3 to mesh- 4 and $0.93 \%$ from mesh- 4 to mesh-5. Hence, mesh5 with 8,539,682 elements is sufficient to characterize the performance of the straightchannel. Similar trend is also observed for the average temperature and pressure drop development in the segmented micro-channel. The variation in average temperature for segmented micro-channel is about $2.85 \%$ from mesh- 1 to mesh-2, $0.32 \%$ from mesh-2 to mesh-3, $0.13 \%$ from mesh-3 to mesh- 4 and $0.11 \%$ from mesh- 4 to mesh- 5 . The variation of pressure drop is about $4.78 \%$ from mesh- 1 to mesh-2, $3.31 \%$ from mesh-2 to mesh-3, $0.73 \%$ from mesh-3 and mesh-4 and $0.75 \%$ from mesh-4 to mesh-5. Therefore, segmented micro-channel with 28,963,841 elements is sufficient to characterize the heat transfer and flow performance. Fig. 2 illustrate the typical structured mesh of the straight-channel.

\subsection{Optimization}

\subsubsection{Taguchi method}

The Taguchi method was first introduced by Genichi Taguchi to improve the process and product quality based on statistical concepts and tools. This method helps to identify the possible combinations of factor to produce the best solution at minimum cost and time [31-32]. In the current study, the Taguchi method is applied to determine the microchannel design parameters that will improve the thermal performance and flow characteristic to derive an optimized micro-channel design. Instead of using full factorial analysis which requires a total of 729 runs of the simulation, the orthogonal array L27, 
which consists of six three-level factors and a total of 27 runs is used to optimize the segmented micro-channel heat sink. The noise factor is not considered in the analysis. The factor level used to optimize the segmented micro-channel is tabulated in Table 4 and the orthogonal array simulation plan is tabulated in Table 5. In total there are six different factors considered in this study, such as fin width (W), fin length (L), fin transverse length $(T)$, number of segments, channel width $(C)$ and mass flow rate. The aim of this optimization process is to obtain maximum specific performance, minimum pressure drop and minimum variation of temperature.

\subsubsection{Signal to noise ratio}

A loss function is used in the Taguchi method to calculate the deviation between simulation results and desired value. This loss function is then converted to Signal-toNoise ratio (SNR). There are three different types of quality characteristic concerning the target design in the Taguchi method analysis, which are known as "Larger the best", "Nominal the best" and "Smaller the best" as described in Eq. 6- Eq. 8 [15, 32]. Since the aim of the study is to achieve higher heat transfer performance with minimum pressure drop and variation of temperature, it is desired to have the highest value for the specific performance and lowest value for the pressure drop and variation of temperature. Therefore, "Larger the best” as in Eq. 6 will be used for specific performance and "smaller the best" will be used for the pressure drop and variation of temperature. A high value of $\eta$ indicates a good performance [15-31].

Larger the best

$$
\eta=-10 \log _{10}\left(\frac{1}{n} \sum_{i=1}^{n} \frac{1}{Y_{i}^{2}}\right)
$$


Smaller the best

$$
\eta=-10 \log _{10}\left(\frac{1}{n} \sum_{i=1}^{n} Y_{i}^{2}\right)
$$

Nominal the best

$$
\eta=-10 \log _{10}\left(\frac{1}{n} \sum_{i=1}^{n} \frac{\mu^{2}}{\sigma^{2}}\right)
$$

$Y_{i} \quad$ Performance value of the simulation $i^{\text {th }}$.

$\mathrm{n} \quad$ Number of simulation run.

\subsubsection{Analysis of variance (ANOVA)}

The Analysis of variance (ANOVA) is used to analyze the results of the orthogonal array experiment to identify the effect of varying contributed by each factor [33-34]. It is also an important technique to analyze the effect of unconditional factors on a response. In this study, the design parameters that can reduce the variation are identified by assessing the amount of variation in the responses through ANOVA. In the Taguchi method, there are three different types of target design that consider as signal to noise ratio. The quality of the product will be improved if the signal to noise ratio is high. In this study, "Larger the best” is used as the optimization criteria for specific performance while "smaller the best" is used as the optimization criteria for pressure drop and variation of temperature. Lastly, the contribution ratio for each design parameters is determined through ANOVA analysis. The influence of each factor on the performance of the microchannel heat sink can be identified from the percentage of contribution of each control factor. Fisher test (F-test) with $95 \%$ of confidence level $(\mathrm{P}<0.05)$ is used to assess the significance of individual parameter on specific performance, pressure drop and variation of temperature. Variance of the corresponding parameter are compared with residual variance and estimated as mean square of the parameter to the mean square of variance 
to derive the F-value for F-test. F-value is usually taken when it is greater or equal to unity. When P-value is less than 0.05 , the parameter is considered to have a significant effect on the performance characteristics and vice versa [35].

\subsubsection{Grey Relational Analysis (GRA)}

Grey Relational Analysis (GRA) applies the information from the grey system to evaluate the design parameters qualitatively for multiple performance characteristics. Level of similarity and variability in the design parameters are the fundamental components of GRA [36]. For example, it is desired to have a highest specific performance and lowest pressure drop and variation of temperature simultaneously for this study. The optimization of the segmented micro-channel heat sink is performed in the following steps:

1. The simulation results of the specific performance are normalized according to Eq. 9 while pressure drop and variation of temperature are normalized according to Eq. 10.

2. The grey relational coefficient (GRC) is calculated according to Eq. 11.

3. The grey relational grade (GRG) is calculated according to the weighting assigned for specific performance, pressure drop and variation of temperature as in Eq. 12. The highest GRG among all candidate schemes will be the best choice, while the priority of all other candidates can be easily sequenced by their GRG value.

There are three different criteria for normalization such as largest the best, nominal the best and smaller the best. However, only two criteria are used which is larger the best for specific performance and smaller the best for pressure drop and variation temperature. The simulation results are normalized to a range between 0 and 1 according to Eq. 9 and Eq. 10 [37].

Larger the best: 


$$
x_{i}^{*}(k)=\frac{x_{i}^{0}(k)-\min x_{i}^{0}(k)}{\max x_{i}^{0}(k)-\min x_{i}^{0}(k)}
$$

Smaller the best:

$x_{i}^{*}(k)=\frac{\max x_{i}^{0}(k)-x_{i}^{0}(k)}{\max x_{i}^{0}(k)-\min x_{i}^{0}(k)}$

$x_{i}^{0}(k)$ is the normalized value of the $k^{\text {th }}$ element in the $i^{\text {th }}$ sequence.

$\max x_{i}^{0}(k)$ is the largest value of $x_{i}^{0}(k)$.

$\min x_{i}^{0}(k)$ is the smallest value of $x_{i}^{0}(k)$.

Next, the Grey Relational Coefficient (GRC) is computed. The grey coefficient is defined by the equation below:

$$
\xi_{i}(k)=\frac{\Delta_{\min }+\psi \Delta_{\max }}{\Delta_{0 i}(k)+\psi \Delta_{\max }}
$$

$\Delta_{0 i}$ is the deviation sequence between reference sequence and the comparable sequence with $x_{0}^{*}(k)=1$.

$$
\begin{aligned}
& \Delta_{0 i}=\left\|x_{0}^{*}(k)-x_{i}^{*}(k)\right\|, \\
& \Delta_{\min }=\min _{\forall j \in i} \min _{\forall k}\left\|x_{0}(k)-x_{j}(k)\right\|, \\
& \Delta_{\max }=\max _{\forall j \in i} \max _{\forall k}\left\|x_{0}(k)-x_{j}(k)\right\|,
\end{aligned}
$$

$x_{0}^{*}(k)$ is the referential sequence;

$x_{i}^{*}(k)$ is the comparative sequence;

$\Delta_{\min } \quad$ Smallest value of $\Delta_{0 i}, 0$.

$\Delta_{\max } \quad$ Largest value of $\Delta_{0 i}, 1$

$\psi$ is the distinguishing or identification coefficient with $0 \leq \Psi \leq 1$, the value depends on the requirements of real system. The value is chosen to magnify the difference between the relational coefficients. In general, $\psi=0.5$ is used [38]. 
Finally, Grey Relational Grade (GRG) as in Eq. 12 is calculated after deriving the GRC value. The GRG is taken as the single representative of the multiple quality responses [38].

$$
\gamma_{i}=\frac{1}{\sum_{k=1}^{n} w_{k}} \sum_{k=1}^{n} w_{k} \xi_{i}(k)
$$

where

$\gamma_{i} \quad$ Overall grey relational grade for $i^{\text {th }}$ experiment.

$w_{k} \quad$ Normalized weight value of $k^{\text {th }}$ performance characteristic.

The weightage used to identify the optimum design for the micro-channel is shown in Table 6.

\subsection{Data Processing}

The heat transfer from the micro-channel heat sink to the water can be calculated using Eq. 13 and Eq. 14 [15, 21]:

$\dot{Q}_{\text {total }}=\dot{Q}_{c o n v}+\dot{Q}_{\text {rad }}+\dot{Q}_{\text {loss }}$

where

$\dot{Q}_{\text {conv }}=\dot{m} C_{p}\left(T_{\text {out }}-T_{\text {in }}\right)$

$\dot{Q}_{c o n v}$ Amount of heat dissipated through convection, W

$\dot{Q}_{\text {rad }} \quad$ Amount of heat dissipated through radiation, W

$\dot{Q}_{\text {loss }} \quad$ Amount of heat loss due to poor insulation, W

$\dot{m} \quad$ Mass flow rate of water, kg.s $\mathrm{s}^{-1}$

$C_{p} \quad$ Specific heat capacity of water, $\mathrm{J} \cdot \mathrm{kg}^{-1} \cdot \mathrm{K}^{-1}$

$T_{\text {out }} \quad$ Outlet temperature, $\mathrm{K}$

$T_{\text {in }} \quad$ Inlet temperature, $\mathrm{K}$

The heat transfer from the micro-channel heat sink by convection can be calculated by Eq. 15 [15, 21]: 
$\dot{Q}_{c o n v}=\bar{h} A_{s}\left[\bar{T}_{s}-\left(\frac{T_{o u t}+T_{\text {in }}}{2}\right)\right]$

$\bar{h} \quad$ Convection heat transfer coefficient, $\mathrm{W} \cdot \mathrm{m}^{-2} \cdot \mathrm{K}^{-1}$

$A_{s} \quad$ Total heat transfer area, $\mathrm{m}^{2}$

$\bar{T}_{S} \quad$ Average surface temperature, $\mathrm{K}$

In this study, radiative heat loss is neglected, and it is also assumed that the test section is well insulated. Hence, second and last terms in Eq. 13 are neglected and Eq. 13 can be further reduce to

$$
\dot{Q}_{\text {total }}=\dot{Q}_{\text {conv }}
$$

As a result, the heat transfer rate to the water is equal to the heat loss from the microchannel heat sink.

$$
\bar{h}=\frac{\dot{Q}_{c o n v}}{A_{s}\left[\bar{T}_{s}-\left(\frac{T_{o u t}+T_{\text {in }}}{2}\right)\right]}
$$

The Nusselt number is calculated using the Eq. 18:

$$
N u=\frac{\bar{h} D_{h}}{k}
$$

$D_{h} \quad$ Hydraulic diameter, $m$

$k \quad$ Thermal conductivity of water, $\mathrm{W} \cdot \mathrm{m}^{-1} \cdot \mathrm{K}^{-1}$

Hydraulic diameter is calculated using the equation below:

$$
D_{h}=\frac{4 V_{f}}{A_{f}}
$$

$V_{\mathrm{f}} \quad$ Total fluid volume inside the heat sink, $\mathrm{m}^{3}$

$A_{\mathrm{f}} \quad$ Total convective heat transfer area in contact with the fluid, $\mathrm{m}^{2}$

The Reynolds number for the cooling fluid is computed using Eq. 20 [15, 39]:

$$
R e=\frac{\rho U_{\infty} D_{h}}{\mu}
$$

$\rho \quad$ Density of water, kg.m $\mathrm{m}^{-3}$ 
$U_{\infty} \quad$ Inlet velocity of water, $\mathrm{m} . \mathrm{s}^{-1}$

$\mu \quad$ Dynamic viscosity of water, $\mathrm{kg} \cdot \mathrm{m}^{-1} \cdot \mathrm{s}^{-1}$

The friction factor ( $f$ ) of the micro-channel is defined by Eq. 21 [39]:

$$
f=\frac{A_{c}}{A_{s}} \frac{2 \Delta p \rho}{G^{2}}
$$

$\Delta p \quad$ Pressure drop through heat sink, $\mathrm{Pa}$

$\rho \quad$ Density of water, kg.m $\mathrm{m}^{-3}$

$A_{c} \quad$ Free flow area, $\mathrm{m}^{2}$

G Mass flux of water based on minimum flow area, $\left(\frac{\dot{m}}{A_{c}}\right) \mathrm{kg} \cdot \mathrm{m}^{-2} \mathrm{~s}^{-1}$

$A_{c} / A_{s} \quad$ Ratio of free flow area to total heat transfer area can be defined as $r_{h} / L$

$r_{h} \quad$ Hydraulic radius, $m$

$L \quad$ Length of the heat sink, $m$

For comparison of different type of heat sink design, specific performance as in Eq. 22 is used [40]. The formula consider the change of the average temperature of the heat sink per unit volume of heat generated.

$$
\dot{Q}_{\text {spec }}=\frac{\dot{Q}}{V \Delta \theta}
$$

$\dot{Q} \quad$ Amount of heat generated, W

V Volume of the heat sink, $\mathrm{m}^{3}$

$\Delta \theta \quad$ Change of temperature, $\mathrm{K}$

Thermal resistance of the heat sink can be calculated using the equation below [1]:

$$
\theta=\frac{T_{\max }-T_{\text {in }}}{Q}
$$

$T_{\max } \quad$ Maximum bottom temperature, $\mathrm{K}$

$T_{\text {in }} \quad$ Inlet fluid temperature, $\mathrm{K}$

Q Total heat generation, W 
Pumping power consumed to deliver the flow needed is defined using Eq. 24 [1].

$W_{p p}=\dot{V} \Delta p$

$\dot{V} \quad$ Volumetric flow rate, $\mathrm{m}^{3} \mathrm{~s}^{-1}$

\section{Result and Discussion}

\subsection{Straight-channel}

Maximum temperature and variation of temperature are the key components in determining the life span of the electronic devices. It is noted that optimum junction temperature for electronic devices is about $85{ }^{\circ} \mathrm{C}$ [41]. Evolution of the average surface temperature and variation of temperature on the heated surface for the straight-channel is illustrated in Fig. 3. It is ascertained that the average surface temperature and variation of temperature are inversely proportional to the mass flow rate of water. In order to achieve an operating temperature which is less than $85{ }^{\circ} \mathrm{C}$, at least $40 \mathrm{gs}^{-1}$ of water is required. However, the recorded temperature variation is very high, which is about $13.2{ }^{\circ} \mathrm{C}$. This may be attributed to the continuous development of the thermal boundary layer in the straight-channel. Hence, higher flow rate is necessary in order to subdue the development of thermal boundary layer effect. As shown in Fig. 3, at least $100 \mathrm{gs}^{-1}$ of water is needed to achieve a temperature difference of about $4.5{ }^{\circ} \mathrm{C}$. Temperature contour plot of the straight-channel at $100 \mathrm{gs}^{-1}$ of water is illustrated in Fig. 4. The maximum and minimum temperatures of the straight-channel heat sink are recorded at $56.8{ }^{\circ} \mathrm{C}$ and $52.3{ }^{\circ} \mathrm{C}$, respectively. The variation of temperature across the micro-channel is approximately 4.5 ${ }^{\circ} \mathrm{C}$.

Besides, higher pumping power is needed to push the coolant through the straightchannel. This is further evidenced by the pumping power versus mass flow rate of water plot in Fig. 5. It is shown that pumping power needed for the straight-channel is increasing exponentially increasing with the mass flow rate of the coolant. At a flow rate of 100 gs $^{-}$ 
${ }^{1}$, the required pumping power is about $2.38 \mathrm{~W}$. Correlation of Nusselt number versus Reynolds number and friction factor versus Reynolds number are derived from the regression analysis and can be expressed by Eq. 25 and Eq. 26, respectively.

$$
\begin{aligned}
& N u=0.0435 \operatorname{Re}^{0.7318} \operatorname{Pr}^{1 / 3} \\
& f=0.256 R e^{-0.227}
\end{aligned}
$$

\subsection{Comparison with correlations}

Thermal management using mini-channel and micro-channel as the cooling solution in the electronic devices has attracted great attention from researchers recently. In liquid cooling, the conventional physical and mathematical correlations describing the heat transfer and fluid flow in conventional channel can be applied on the micro-channel and mini-channel for a small variations of surface roughness and wall thickness. Thus, the Nusselt number of the simulation results can be compared with Colburn, Dittus-Boelter, Sieder-Tate and Gnielinski correlation as shown in Eq. 27, Eq. 28, Eq. 29 and Eq. 30, respectively [42].

$$
\begin{aligned}
& \mathrm{Nu}=0.023 \operatorname{Re}^{4 / 5} \operatorname{Pr}^{1 / 3} \\
& \mathrm{Nu}=0.023 \operatorname{Re}^{4 / 5} \operatorname{Pr}^{0.4} \\
& N u=0.027 \operatorname{Re}^{4 / 5} \operatorname{Pr}^{1 / 3}\left(\frac{\mu}{\mu_{s}}\right)^{0.14}
\end{aligned}
$$

$\mu \quad$ Fluid viscosity at the bulk fluid temperature, $\mathrm{kg} \cdot \mathrm{m}^{-1} \cdot \mathrm{s}^{-1}$

$\mu_{s} \quad$ Fluid viscosity at the heat-transfer boundary surface temperature, $\mathrm{kg} \cdot \mathrm{m}^{-1} \cdot \mathrm{s}^{-1}$

$$
N u=\frac{(f / 8)\left(R e_{D}-1000\right) P r}{1+12.7(f / 8)^{1 / 2}\left(\operatorname{Pr}^{2 / 3}-1\right)}
$$

On the other hand, the friction factor of the simulation results can be compared with Blasius and Petukhov correlation as shown in Eq. 31 and Eq. 32, respectively [42].

$$
\begin{aligned}
& f=0.3164 \mathrm{Re}^{-0.25} \\
& f=(0.790 \ln \mathrm{Re}-1.64)^{-2}
\end{aligned}
$$


Fig. 6 and Fig. 7 illustrate the comparison results of Nusselt number and friction factor, respectively. The average differences of Nusselt number for Colburn, DittusBoelter, Sieder-Tate and Gnielinski correlations as compared to the simulation results are about $3.4 \%, 9.0 \%, 13.4 \%$ and $2.5 \%$, respectively, as shown in Fig. 6. Among all correlations, Colburn correlation is in a good agreement with each other with average difference of $3.4 \%$. On the hand, the average differences in the friction factor for Blasius and Petukhov correlations as compared to the simulation results are about $0.5 \%$ and 1.9 $\%$, respectively, as demonstrated in Fig. 7. Large deviation is found when the flow rate is about 30 gs $^{-1}$ near to transition region while the conventional correlations are valid for fully developed region. In addition, the test section used for conventional correlations is circular while test section used in this study is rectangular. Therefore, a slight variation is expected for the simulation results and conventional correlations. In short, simulation results correlate well with the conventional correlations for Nusselt number and friction factor. CFD simulation of the heat sink has shown to be useful in providing insights of the different flow phenomenon and it offers a clear physical understanding of the heat transfer and flow field of the heat sink which is difficult to obtain through experimental works.

\subsection{Segmented micro-channel}

It is always a challenging task to simultaneously increase the heat transfer rate while at the meantime, reduce the pressure drop and temperature variation in a micro-channel heat sink. Therefore, specific performance, pressure drop and temperature variation of the segmented micro-channel need to be explored. The considered design parameters are fin width, fin length, fin transverse length, number of segments, channel width, and different mass flow rate. Each design parameter has three levels as stated in Table 4. Hence, a systematic approach is used to analyze the simulation results by constructing a simulation 
plan for the segmented micro-channel. In order to produce an optimized design, the simulation results are analyzed to determine the effect each design parameter on the specific performance, pressure drop and temperature variation. The simulation results are further converted to signal to noise ratio for the analysis purpose. The signal to noise ratio for the specific performance, pressure drop and variation of temperature is tabulated in Table 7.

The response diagram for the design parameter on the specific performance, pressure drop and temperature variation are shown in Fig. 8, Fig. 9 and Fig. 10, respectively. On the other hand contribution ratio of each design parameter on the specific performance, pressure drop and temperature variation are illustrated in Fig. 11. The larger slope in the figure indicates that the design parameter has a more significant impact on the performance characteristic. Based on the results shown in Fig. 8 and Fig. 11, the most influential parameters on the specific performance are ranked as follows: mass flow rate (F) at level $2\left(15 \mathrm{gs}^{-1}\right)$, channel width (E) at level $3(0.3 \mathrm{~mm})$, fin width (A) at level 2 (2 $\mathrm{mm}$ ), number of segments (D) at level 1 (3), fin length (B) at level 3 (1 mm) and fin transverse distance (C) at level $3(2 \mathrm{~mm})$. The specific performance is enhanced by increasing the mass flow rate of water, as well as reducing the channel width and fin width. The maximum specific performance is obtained at $15 \mathrm{gs}^{-1}$ of water, $0.3 \mathrm{~mm}$ of channel width and $2 \mathrm{~mm}$ of fin width. Besides, it is also observed that the specific performance does not change significantly with the transverse distance between the fins and follow by the number of segments present in the segmented micro-channel heat sink. Therefore, the optimal parameter setting for the maximum specific performance is A2B3C3D1E3F2.

According to the results depicted in Fig. 9 and Fig. 11, the most effective design parameters with respect to the pressure drop are as follows: fin width (A) at level 3 (1 
$\mathrm{mm})$, mass flow rate $(\mathrm{F})$ at level $3\left(10 \mathrm{gs}^{-1}\right)$, channel width $(\mathrm{E})$ at level $1(1 \mathrm{~mm})$, fin length (B) at level $2(2 \mathrm{~mm})$, fin transverse distance (C) at level $1(5 \mathrm{~mm})$ and number of segments (D) at level 1 (3). The pressure drop dramatically decreases as a result of reducing the fin width, reducing the flow rate of water and increasing of channel width. Minimum pressure drop is obtained when the fin width is $1 \mathrm{~mm}$, the mass flow rate is 10 gs $^{-1}$ and the channel width is $1 \mathrm{~mm}$. Furthermore, it is also noticed that number of segments does not affect the pressure drop significantly. Although there is no important change in the pressure drop, micro-channel heat sink with three segments is the optimum setting for the pressure drop parameter. Hence, the optimal parameter setting for the minimum pressure drop is A3B2C1D1E1F3.

According to Fig. 10 and Fig. 11, the most influential parameters on the temperature variation are arranged as follows: number of segments (D) at level 1 (3), mass flow rate (F) at level $1\left(20 \mathrm{gs}^{-1}\right)$, channel width (E) at level $1(1 \mathrm{~mm})$, fin transverse distance (C) at level 1 (5 mm), fin length (B) at level $2(2 \mathrm{~mm})$ and fin width (A) at level $3(1 \mathrm{~mm})$. The variation of temperature reduces with higher number of segments, higher mass flow rate of water and longer channel width. The minimum variation of temperature is achieved when the number of segment is three, mass flow rate is $20 \mathrm{gs}^{-1}$ and channel width is 1 mm. Furthermore, it is also observed that the width of fin does not affect the variation of temperature significantly. Although width of fin is not an important factor affecting the temperature variation, fin width of about $1 \mathrm{~mm}$ is the optimum setting for the minimum variation of temperature. Thus, the optimal parameter setting for the minimum temperature variation is A3B2C1D1E1F1.

Based on the above analysis, it is clearly shown that it is easy to evaluate the effects of optimum design parameters on each of the target response separately. If there are multiple responses involved in the optimization process, there is no single design 
parameters that can satisfy all the required responses. Hence, a more systematic approach is employed, namely Grey relational analysis, to derive the optimum design parameter to compromise each response by using the weighting method as tabulated in Table 6 . In this study, variation of temperature is the most desired response follow by the specific performance and pressure drop. Therefore, the weighting values for specific performance, pressure drop and variation of temperature are set to $0.3,0.3$ and 0.4 , respectively. Firstly, the simulation results are normalized to a range of 0 and 1 , as mentioned in section 2.4.4. Next, grey relational coefficient and grey relational grade are computed as tabulated in Table 8. Finally, the response graph of the grey relational grade according to the $\mathrm{L}_{27}$ orthogonal array simulation design plan is plotted in Fig. 12. As shown in Fig. 12, the most ideal candidate for the optimal design parameters are fin width (A) at level 3 (1 $\mathrm{mm})$, fin length (B) at level $2(2 \mathrm{~mm})$, fin transverse distance $(\mathrm{C})$ at level $1(5 \mathrm{~mm})$, number of segments (D) at level 1 (3), channel width (E) at level 1 (1 mm) and mass flow rate $(\mathrm{F})$ at level $2\left(15 \mathrm{gs}^{-1}\right)$. The optimized design parameter for segmented micro-channel heat sink is A3B2C1D1E1F2. By mapping the orthogonal array simulation design plan in Table 5 with the plots in Fig. 12, it is found out that the simulations corresponding to the optimum conditions are not performed yet. Hence, a confirmation test is required to be conducted at the optimum design parameters to validate the prediction.

Development of the average surface temperature and variation of temperature of the optimized segmented micro-channel heat sink is illustrated in Fig. 13. As expected, the average temperature and the variation of temperature are decrease progressively with the mass flow rate of water. $5 \mathrm{gs}^{-1}$ of water is sufficient to reduce the temperature of the heated surface to less than $85^{\circ} \mathrm{C}$. However, the variation of temperature is still above the desired range which is about $14.6{ }^{\circ} \mathrm{C}$. In order to achieve the temperature variation that is 
less than $3{ }^{\circ} \mathrm{C}$, about $15 \mathrm{gs}^{-1}$ of water is needed and the average temperature of the heated surface will be reduced to approximately $56.6^{\circ} \mathrm{C}$.

In the segmented micro-channel heat sink, the design parameters such as fin dimension, channel width and number of segments are changed gradually and this evolution will alter the flow behaviour in the micro-channel. Fluid mixing and reinitialization of the thermal boundary layer are the two main activities occurred in the segmented micro-channel heat sink. Fluid mixing and thermal boundary redevelopment will help in promoting more uniform temperature distribution across the heated surface. Hence, the thermal performance of the segmented micro-channel heat sink is better than that of the straight-channel. Furthermore, as the number of segments increases, the flow channel width is reduced and the number of fin present in the downstream is also increased. The total heat transfer area in the downstream is inevitably increased and temperature distribution is more uniform and the occurrence of the hot spot will be reduced. Temperature contour plot of the segmented micro-channel heat sink under 15 $\mathrm{gs}^{-1}$ of water is shown in Fig. 14. The maximum and minimum temperatures of the segmented micro-channel heat sink are recorded at $57.8^{\circ} \mathrm{C}$ and $54.8^{\circ} \mathrm{C}$, respectively. The variation of temperature across the novel segmented micro-channel heat sink is approximately $3.0^{\circ} \mathrm{C}$.

Pumping power needed for the segmented micro-channel heat sink under different mass flow rate is illustrated in Fig. 15. The pumping power is exponentially increasing with the mass flow rate of water. At mass flow rate of $15 \mathrm{gs}^{-1}$, about $0.13 \mathrm{~W}$ of pumping power is needed. From the simulation result, it is clearly shown that the segmented microchannel heat sink is capable to improve the thermal performance tremendously with lower pumping power, i.e. about 18 times less than that of the straight-channel heat sink. Based on the conjugate heat transfer analysis, correlation of Nusselt number versus Reynolds 
number and friction factor versus Reynolds number derived from the regression analysis are defined in Eq. 33 and Eq. 34, respectively. The Nusselt number and friction correlations can be used in the preliminary design of the cooling solution for the high heat load devices such as electronic chips, solar cell, electric vehicle controller, laser gun, etc.

$$
\begin{aligned}
N u & =2.468 R e^{0.256} \operatorname{Pr}^{1 / 3} \\
f & =3.159 R e^{-0.205}
\end{aligned}
$$

\subsection{Comparison of segmented micro-channel with straight-channel}

Comparison of the thermal resistance and variation of temperature for the segmented micro-channel and straight-channel heat sink are shown in Fig. 16 and Fig. 17, respectively. As shown in Fig. 16, thermal resistance for segmented micro-channel and straight-channel heat sink decreases with the inlet mass flow rate of water and the slope decreases gradually. This can be attributed to the reduction of convective thermal resistance. In comparison to the thermal resistance of straight-channel heat sink, the thermal resistance of the segmented micro-channel heat sink is comparatively lower. At $30 \mathrm{gs}^{-1}$, thermal resistances for the segmented micro-channel and straight-channel are 0.02589 and 0.08115 , respectively. Hence, the thermal performance of the segmented micro-channel heat sink is threefold of the straight-channel. Similar trend is also observed for the variation of temperature for the segmented micro-channel and straight-channel heat sink. At 30 gs $^{-1}$, variations of temperature for the segmented micro-channel and straight-channel are $1.2{ }^{\circ} \mathrm{C}$ and $15.0{ }^{\circ} \mathrm{C}$, respectively. The improvement on the variation of temperature is about 12.5 times of the straight-channel. The effect of the mass flow rate on pressure drop is shown in Fig. 18. The pressure drop of the segmented microchannel and straight-channel heat sink increases gradually with respect to the inlet mass flow rate of water. As compared to the pressure drop of straight-channel heat sink, the pressure drop of the segmented micro-channel heat sink is comparatively higher. At 30 
$\mathrm{gs}^{-1}$, pressure drops of the segmented micro-channel heat sink is recorded at $30436 \mathrm{~Pa}$, which is about 10 times higher than that of the straight-channel heat sink. However, for the electronic cooling, minimum variation of temperature is the priority consideration. In order to achieve variation of temperature less than $5{ }^{\circ} \mathrm{C}$, straight-channel heat sink requires mass flow rate at least $100 \mathrm{gs}^{-1}$ with pressure loss of $23733 \mathrm{~Pa}$. On the other hand, segmented micro-channel heat sink only requires mass flow rate of 15 gs $^{-1}$ with only 8522 Pa of pressure drop, which is 2.8 times less than the straight-channel heat sink. In short, the optimized structure of the segmented micro-channel heat sink provides excellent thermal performance as compared to the straight-channel heat sink with minimum energy consumption.

\section{Conclusions}

In this study, CFD simulation on the straight-channel and segmented micro-channel heat sink is conducted. The effects of various design parameters, such as fin width, fin length, fin transverse distance, number of segments, channel width and mass flow rate on the heat transfer and flow characteristics, are optimized using Taguchi-Grey method. The optimal parameters have been assigned to maximize the specific performance, minimize pressure drop and minimize variation of temperature in the micro-channel heat sink. The most important design parameters affecting the specific performance of the segmented micro-channel heat sink are flow rate, channel width, fin width and number of segments. The maximum specific performance of the segmented micro-channel heat sink is found to be $15 \mathrm{gs}^{-1}$ mass flow rate, $0.3 \mathrm{~mm}$ channel width, $2 \mathrm{~mm}$ fin width and 3 segments micro-channel. The most important design parameters affecting the pressure drop in the segmented micro-channel heat sink are fin width, flow rate, channel width and fin length. The pressure drop in the segmented micro-channel heat sink can be effectively reduced by controlling these parameters. The minimum pressure drop of the segmented micro- 
channel heat sink are recorded with the use of $1 \mathrm{~mm}$ fin width, $10 \mathrm{gs}^{-1}$ mass flow rate, 1 mm channel width and $2 \mathrm{~mm}$ fin length. The most important design parameters affecting the variation of temperature in the segmented micro-channel heat sink are number of segments, mass flow rate, channel width and fin transverse distance. The variation of temperature across the segmented micro-channel heat sink can be effectively reduced by controlling these parameters. Minimum variation of temperature is observed using 3 segments micro-channel, $20 \mathrm{gs}^{-1}$ mass flow rate, $1 \mathrm{~mm}$ channel width and $5 \mathrm{~mm}$ fin transverse distances. When all desired responses are taken into account together, grey relation analysis is applied to optimize the segmented micro-channel heat sink. Optimum results are obtained when $1 \mathrm{~mm}$ fin width, $2 \mathrm{~mm}$ fin length, $5 \mathrm{~mm}$ fin transverse distance, 3 segments micro-channel, $1 \mathrm{~mm}$ channel width and $15 \mathrm{gs}^{-1}$ mass flow rate are applied. The heat transfer performance of the straight-channel is weakened along the flow direction. This is due to the continuous development of the thermal boundary layer and reduction of the cooling capacity of water. On the other hand, segmented micro-channel is able to enhance the overall cooling performance that is impossible to be achieved through conventional straight-channel heat sink. Heat transfer enhancement of the segmented micro-channel can be attributed to the fluid mixing and frequent thermal boundary layer development at each fin. Furthermore, increasing the total heat transfer area will further improve the heat transfer performance at downstream. Based on the findings obtained in this study, it can be concluded that segmented micro-channel heat sink is an alternative solution for thermal management system in high heat load electronic devices with minimum pumping power consumption.

\section{Acknowledgment}

This work was supported by Science fund Grant No. 03-02-11-SF2016 from Ministry of Science, Technology and innovation, Malaysia. 
Accepted by Applied Energy for publication on 31/March 2018 


\section{References}

1. Lie XL, Tao WQ, He YL. Numerical study of turbulent heat transfer and pressure drop characteristics in a water-cooled minichannel heat sink. Trans, ASME-J Elec Pack 2007;129:247-255.

2. Gong L, Zhao J, Huang S. Numerical study on layout of microchannel heat sink for thermal management of electronic devices. J Appl Therm Eng 2015;88:480-490.

3. Xie G, Chen Z, Sunden B, Zhang W. Comparative study of flow and thermal performance of liquid-cooling parallel-flow and counter-flow double-layer wavy microchannel heat sink. Numer Heat Trans, Part A. 2013;64:30-55.

4. Naqiuddin NH, Saw LH, Yew MC, Yusof F, Ng TC, Yew MK. Overview of microchannel design for high heat flux application. Renew Sust Energ Rev 2018;82:901914.

5. Salman BH, Mohammed HA, Munisamy KM, Kherbeet AS. Characteristic of heat transfer and fluid flow in microtube and microchannel using conventional fluids and nanofluids: A review. Renew Sust Energ Rev 2013;28:848-880.

6. Tuckerman DB, Pease RFW. High-performance heat sinking for VLSI. IEEE Electron Device Lett 1981;2:126-129.

7. Balasubramanian K, Lee PS, Jin LW, Chou SK, Teo CJ, Gao S. Experimental investigations of flow boiling heat transfer and pressure drop in straight and expanding microchannels - A comparative study. Int J Therm Sci 2011;50:2413-2421.

8. Lin L, Zhao J, Lu G, Wang XD, Yan WM. Heat transfer enhancement in microchannel heat sink by wavy channel with changing wavelength/amplitude. Int J Therm Sci 2017;118:423-434.

9. Chai L, Xia GD, Wang HS. Laminar flow and heat transfer characteristic of interrupted microchannel heat sink with ribs in the transverse microchambers. Int $\mathrm{J}$ Therm Sci 2016;110:1-11.

10. Pan $\mathrm{M}, \mathrm{Wu} \mathrm{Q}$, Jiang L, Zeng D. Effect of microchannel structure on the reaction performance of methanol steam reforming. Appl Energ 2015;154:416-427.

11. Law M, Lee PS. A comparative study of experimental flow boiling heat transfer and pressure characteristics in straight- and oblique-finned microchannels. Int J Heat Mass Trans 2015;85:797-810.

12. Jin LW, Lee PS, Kong XX, Fan Y, Chou SK. Ultra-thin minichannel LCP for EV battery thermal management. Appl Energ 2014;113:1786-1794.

13. Hussien AA, Abdullah MZ, Al-Nimr MA. Single-phase heat transfer enhancement in micro/minichannels using nanofluids: Theory and applications. Appl Energ 2016;164:733-755. 
14. Ahmed HE, Salman BH, Kherbeet AS, Ahmed MI. Optimization of thermal design of heat sinks: A review. Int J Heat Mass Trans 2018;118:129-153.

15. Sahin B, Yakut K, Kotcioglu I, Celik C. Optimum design parameters of a heat exchanger. Appl Energ 2005;82:90-106.

16. Chen WH, Huang SR, Lin YL. Performance analysis and optimum operation of a thermoelectric generator by Taguchi method. Appl Energ 2015;158:44-54.

17. Pandey N, Murugesan K, Thomas HR. Optimization of ground heat exchangers for space heating and cooling applications using Taguchi method and utility concept. Appl Energ 2017;1890:421-438.

18. Srikanth R, Nemani P, Balaji C. Multi-objective geometric optimization of a PCM based matrix type composite heat sink. Appl Energ 2015;156:703-714.

19. Jang D, Yook SJ, Lee KS. Optimum design of a radial heat sink with a fin-height profile for high-power LED lighting applications. Appl Energ 2014;116:260-268.

20. Ansys, ANSYS CFX-Solver modelling guide, Canonsburg: Ansys Inc; 2010.

21. Saw LH, Ye Y, Tay AAO, Chong WT, Kuan SH, Yew MC. Computational fluid dynamic and thermal analysis of Lithium-ion battery pack with air cooling. Appl Energ 2016;177:783-792.

22. Saw LH, Ye Y, Yew MC, Chong WT, Yew MK, Ng TC. Computational fluid dynamics simulation on open cell aluminium foams for Li-ion battery cooling system. Appl Energ 2017;204:1489-1499.

23. Fan Y, Lee PS, Chua BW. Investigation on the influence of edge effect on flow and temperature uniformities in cylindrical oblique-finned minichannel array. Int J Heat Mass Transfer 2014;70:651-663.

24. Wu Z, Caliot C, Bai F, Flamant G, Wang Z, Zhang J, Tian C. Experimental and numerical studies of the pressure drop in ceramic foams for volumetric solar receiver applications. Appl Energ 2010;87:504-513.

25. Menter FR, Kuntz M, Langtry R. Ten years of industrial experience with the SST turbulence model. Turbulence, Heat and Mass Transfer, $4^{\text {th }}$ ed., US: Begell House 2003.

26. Vieser W, Esch T, Menter F. Heat transfer predictions using advanced two equation turbulence models. CFX validation Report; 2002.

27. Bardina, JE, Huang, PG, Coakley, TJ. Turbulence modelling validation testing and development. NASA Technical Memorandum 1997;110446: 1-15. 
28. Sparrow, EM, Abraham, JP, Minkowycz, WJ. Flow separation in a diverging conical duct: effect of Reynolds number and divergence angle. Int J Heat Mass Transfer 2009;52:3079-3083.

29. Lee, GG, Allan, WDE, Boulama, KG. Flow and performance characteristics of an Allison 250 gas turbine S-shaped diffuser: effects of geometry variations. Int J Heat Fluid Flow 2013;42:151-163.

30. Sharma CS, Tiwari MK, Zimmermann S, Brunschwiler T, Schlottig G, Michel B, Poulikakos D. Energy efficient hotspot-targeted embedded liquid cooling of electronics. Appl Energ 2015;138:414-422.

31. Taguchi G. Taguchi techniques for quality engineering. Quality resources. New York; 1987.

32. Kotcioglu I, Cansiz A, Khalaji MN. Experimental investigation for optimization of design parameters in a rectangular duct with plate-fins heat exchanger by Taguchi method. Appl Therm Eng 2013;50:604-613.

33. Roy RK. Design of experiments using the Taguchi Approach: 16 steps to Product and Process Improvement. John Wiley \& Son Inc. New York; 2001.

34. Ross PJ. Taguchi techniques for quality engineering. McGraw-Hill. New York; 1996.

35. Adewale P, Vithanage LN, Christopher L. Optimization of enzyme-catalysed biodiesel production from crude tall oil using Taguchi method. Ener Cov Manag 2017;154:81-91.

36. Tsai $\mathrm{CH}$, Chang CL, Chen L. Applying grey relational analysis to the vendor evaluation model. Int J Comp, Intern Manag 2003; 11: 45-53.

37. Wu, H. H. The introduction of Grey Analysis. Gauli Publishing Co. Taipei; 1996.

38. Dey A, Debnath S, Pandey KM. Optimization of electrical discharge machining process parameters for Al6061/cenosphere composite using grey-based hybrid approach. Trans. Nonferrous Met. Soc. China 2017;27:998-1010.

39. Kays WM, London AL. Compact heat exchangers. $2^{\text {nd }}$ ed. New York: McGraw-Hill, New York; 1964.

40. Smith, EM. Advances in thermal design of heat exchangers. John Wiley \& Sons, Ltd. Chichester, West Sussex, England; 2005.

41. Prajapati YK, Pathak M, Khan MK. Transient heat transfer characteristic of segmented finned microchannels. Exp Therm Fluid Sci 2016;79:134-142.

42. Incropera FP, Dewitt DP, Bergman TL, Lavine A. Fundamentals of heat and mass transfer. $6^{\text {th }}$ ed. John Wiley \& Sons, New York, 2007.

Table 1. Physical properties of water and copper used in the simulations. 


\begin{tabular}{lcccc}
\hline Material & $\rho, \mathrm{kgm}^{-3}$ & $k, \mathrm{Wm}^{-1} \mathrm{~K}^{-1}$ & $C_{p}, \mathrm{Jkg}^{-1} \mathrm{~K}^{-1}$ & $\mu, \mathrm{kgm}^{-1} \mathrm{~s}^{-1}$ \\
\hline Water & 997 & 0.6069 & 4181.7 & 0.0008899 \\
Copper & 8933 & 401 & 385 & - \\
\hline
\end{tabular}

Table 2. Boundary details and settings for the micro-channel in CFD analysis.

\begin{tabular}{lll}
\hline Boundary Name & Boundary details & Value \\
\hline Inlet & Temperature & $30{ }^{\circ} \mathrm{C}$ \\
\multirow{3}{*}{ Outlet } & Turbulence Intensity & $5 \%$ \\
Fluid domain & Pressure outlet & $0 \mathrm{~Pa}$ \\
& Non-contact wall & Non slip \\
& Non-contact wall heat Transfer & Adiabatic \\
Micro-channel domain & Turbulence option & SST model \\
& Initial temperature & $30{ }^{\circ} \mathrm{C}$ \\
\multirow{2}{*}{ Heat source domain } & Non-contact wall heat transfer & Adiabatic \\
& Initial temperature & $30{ }^{\circ} \mathrm{C}$ \\
Holder domain & Non-contact wall heat transfer & Adiabatic \\
& Initial temperature & $30{ }^{\circ} \mathrm{C}$ \\
& Non-contact wall heat Transfer & Adiabatic \\
\hline
\end{tabular}


Table 3. Grid independent test result for straight micro-channel and segmented micro-channel.

\begin{tabular}{|c|c|c|c|c|c|c|c|c|c|}
\hline Mesh No & Mesh-1 & Mesh-2 & $\begin{array}{c}\% \\
\text { deviation }\end{array}$ & Mesh-3 & $\begin{array}{c}\% \\
\text { deviation }\end{array}$ & Mesh-4 & $\begin{array}{c}\% \\
\text { deviation }\end{array}$ & Mesh-5 & $\begin{array}{c}\% \\
\text { deviation }\end{array}$ \\
\hline \multicolumn{10}{|l|}{ Straight channel } \\
\hline Number of element & 604,126 & $1,302,955$ & & $2,376,444$ & & $4,227,917$ & & $8,539,682$ & \\
\hline Average temperature, ${ }^{\circ} \mathrm{C}$ & 95.57 & 97.55 & $2.07 \%$ & 97.58 & $0.03 \%$ & 97.48 & $0.10 \%$ & 97.60 & $0.12 \%$ \\
\hline Pressure drop, $\mathrm{Pa}$ & 2800.56 & 2636.13 & $5.87 \%$ & 2588.93 & $1.79 \%$ & 2542.81 & $1.78 \%$ & 2566.52 & $0.93 \%$ \\
\hline \multicolumn{10}{|l|}{ Segmented } \\
\hline Number of element & $2,331,419$ & $4,389,590$ & & $6,495,016$ & & $12,069,880$ & & $28,963,841$ & \\
\hline Average temperature, ${ }^{\circ} \mathrm{C}$ & 52.01 & 53.49 & $2.85 \%$ & 53.32 & $0.32 \%$ & 53.39 & $0.13 \%$ & 53.45 & $0.11 \%$ \\
\hline Pressure drop, $\mathrm{Pa}$ & 14437.20 & 15127.90 & $4.78 \%$ & 15630.10 & $3.31 \%$ & 15515.50 & $0.73 \%$ & 15631.30 & $0.75 \%$ \\
\hline
\end{tabular}


Table 4. Taguchi method optimization parameter study.

\begin{tabular}{lccc}
\hline \multirow{2}{*}{\multicolumn{1}{c}{ Factor }} & \multicolumn{3}{c}{ Level } \\
\cline { 2 - 4 } & 1 & 2 & 3 \\
\hline A Fin width (W), mm & 4 & 2 & 1 \\
B Fin length (L), mm & 4 & 2 & 1 \\
C Fin transverse distance (T), mm & 5 & 3 & 2 \\
D Number of segments & 3 & 2 & 1 \\
E Channel width (C), mm & 1 & 0.5 & 0.3 \\
F Mass flow rate, gs ${ }^{-1}$ & 20 & 15 & 10 \\
\hline
\end{tabular}

Table 5 Taguchi method simulation plan-L27.

\begin{tabular}{|c|c|c|c|c|c|c|}
\hline \multirow{2}{*}{ Run } & \multicolumn{6}{|c|}{ Parameter and its levels } \\
\hline & A & B & $\mathrm{C}$ & $\mathrm{D}$ & $E$ & $\mathrm{~F}$ \\
\hline 1 & 1 & 1 & 1 & 1 & 1 & 1 \\
\hline 2 & 1 & 1 & 1 & 1 & 2 & 2 \\
\hline 3 & 1 & 1 & 1 & 1 & 3 & 3 \\
\hline 4 & 1 & 2 & 2 & 2 & 1 & 1 \\
\hline 5 & 1 & 2 & 2 & 2 & 2 & 2 \\
\hline 6 & 1 & 2 & 2 & 2 & 3 & 3 \\
\hline 7 & 1 & 3 & 3 & 3 & 1 & 1 \\
\hline 8 & 1 & 3 & 3 & 3 & 2 & 2 \\
\hline 9 & 1 & 3 & 3 & 3 & 3 & 3 \\
\hline 10 & 2 & 1 & 2 & 3 & 1 & 2 \\
\hline 11 & 2 & 1 & 2 & 3 & 2 & 3 \\
\hline 12 & 2 & 1 & 2 & 3 & 3 & 1 \\
\hline 13 & 2 & 2 & 3 & 1 & 1 & 2 \\
\hline 14 & 2 & 2 & 3 & 1 & 2 & 3 \\
\hline 15 & 2 & 2 & 3 & 1 & 3 & 1 \\
\hline 16 & 2 & 3 & 1 & 2 & 1 & 2 \\
\hline 17 & 2 & 3 & 1 & 2 & 2 & 3 \\
\hline 18 & 2 & 3 & 1 & 2 & 3 & 1 \\
\hline 19 & 3 & 1 & 3 & 2 & 1 & 3 \\
\hline 20 & 3 & 1 & 3 & 2 & 2 & 1 \\
\hline 21 & 3 & 1 & 3 & 2 & 3 & 2 \\
\hline 22 & 3 & 2 & 1 & 3 & 1 & 3 \\
\hline 23 & 3 & 2 & 1 & 3 & 2 & 1 \\
\hline 24 & 3 & 2 & 1 & 3 & 3 & 2 \\
\hline 25 & 3 & 3 & 2 & 1 & 1 & 3 \\
\hline 26 & 3 & 3 & 2 & 1 & 2 & 1 \\
\hline 27 & 3 & 3 & 2 & 1 & 3 & 2 \\
\hline
\end{tabular}

Table 6. Weightage for each response.

\begin{tabular}{cccc}
\hline Weightage & \multicolumn{3}{c}{ Response } \\
\cline { 2 - 4 } & $\begin{array}{c}\text { Specific } \\
\text { performance } \\
(\mathrm{SP})\end{array}$ & $\begin{array}{c}\text { Pressure drop } \\
(\mathrm{PD})\end{array}$ & $\begin{array}{c}\text { Temperature variation } \\
(\mathrm{TV})\end{array}$ \\
\hline $\mathrm{w}$ & 0.3 & 0.3 & 0.4 \\
\hline
\end{tabular}


Table 7 Simulation plan of $\mathrm{L}_{27}\left(3^{6}\right)$ for specific performance, pressure drop and temperature variation with their SNR values.

\begin{tabular}{rrrrrrrcccccc}
\hline Run & A & B & C & D & E & F & $\begin{array}{c}\text { Specific } \\
\text { performance }\end{array}$ & SNR & $\begin{array}{c}\text { Pressure } \\
\text { drop }\end{array}$ & S-N & $\begin{array}{c}\text { Temperature } \\
\text { variation }\end{array}$ & SNR \\
\hline 1 & 1 & 1 & 1 & 1 & 1 & 1 & 6783421 & 136.63 & 16515 & -84.36 & 5.5 & -14.82 \\
2 & 1 & 1 & 1 & 1 & 2 & 2 & 8006979 & 138.07 & 14060 & -82.96 & 5.2 & -14.24 \\
3 & 1 & 1 & 1 & 1 & 3 & 3 & 5632229 & 135.01 & 10102 & -80.09 & 6.6 & -16.38 \\
4 & 1 & 2 & 2 & 2 & 1 & 1 & 6486681 & 136.24 & 17259 & -84.74 & 6.2 & -15.87 \\
5 & 1 & 2 & 2 & 2 & 2 & 2 & 7851987 & 137.90 & 18312 & -85.25 & 13.0 & -22.26 \\
6 & 1 & 2 & 2 & 2 & 3 & 3 & 5621733 & 135.00 & 18239 & -85.22 & 17.4 & -24.83 \\
7 & 1 & 3 & 3 & 3 & 1 & 1 & 6403662 & 136.13 & 21260 & -86.55 & 14.2 & -23.07 \\
8 & 1 & 3 & 3 & 3 & 2 & 2 & 7247409 & 137.20 & 34164 & -90.67 & 12.1 & -21.64 \\
9 & 1 & 3 & 3 & 3 & 3 & 3 & 6527874 & 136.30 & 41540 & -92.37 & 14.0 & -22.92 \\
10 & 2 & 1 & 2 & 3 & 1 & 2 & 6114567 & 135.73 & 7316 & -77.29 & 12.1 & -21.62 \\
11 & 2 & 1 & 2 & 3 & 2 & 3 & 6272901 & 135.95 & 7716 & -77.75 & 14.3 & -23.09 \\
12 & 2 & 1 & 2 & 3 & 3 & 1 & 8903969 & 138.99 & 64043 & -96.13 & 7.2 & -17.18 \\
13 & 2 & 2 & 3 & 1 & 1 & 2 & 8789857 & 138.88 & 10560 & -80.47 & 4.3 & -12.71 \\
14 & 2 & 2 & 3 & 1 & 2 & 3 & 7360159 & 137.34 & 5614 & -74.99 & 9.8 & -19.80 \\
15 & 2 & 2 & 3 & 1 & 3 & 1 & 8336032 & 138.42 & 29666 & -89.45 & 5.7 & -15.16 \\
16 & 2 & 3 & 1 & 2 & 1 & 2 & 8405935 & 138.49 & 12636 & -82.03 & 9.3 & -19.37 \\
17 & 2 & 3 & 1 & 2 & 2 & 3 & 6055831 & 135.64 & 7974 & -78.03 & 15.3 & -23.68 \\
18 & 2 & 3 & 1 & 2 & 3 & 1 & 8181100 & 138.26 & 49828 & -93.95 & 11.2 & -20.97 \\
19 & 3 & 1 & 3 & 2 & 1 & 3 & 5029866 & 134.03 & 2412 & -67.65 & 9.4 & -19.48 \\
20 & 3 & 1 & 3 & 2 & 2 & 1 & 7358597 & 137.34 & 10183 & -80.16 & 12.3 & -21.79 \\
21 & 3 & 1 & 3 & 2 & 3 & 2 & 6877786 & 136.75 & 7179 & -77.12 & 17.0 & -24.61 \\
22 & 3 & 2 & 1 & 3 & 1 & 3 & 4857748 & 133.73 & 789 & -57.95 & 11.8 & -21.42 \\
23 & 3 & 2 & 1 & 3 & 2 & 1 & 7924423 & 137.98 & 5365 & -74.59 & 6.8 & -16.60 \\
24 & 3 & 2 & 1 & 3 & 3 & 2 & 7995436 & 138.06 & 6517 & -76.28 & 8.5 & -18.60 \\
25 & 3 & 3 & 2 & 1 & 1 & 3 & 5904962 & 135.42 & 3741 & -71.46 & 4.7 & -13.35 \\
26 & 3 & 3 & 2 & 1 & 2 & 1 & 8176043 & 138.25 & 16222 & -84.20 & 5.7 & -15.06 \\
27 & 3 & 3 & 2 & 1 & 3 & 2 & 7664773 & 137.69 & 11138 & -80.94 & 10.0 & -20.04 \\
\hline & & & & & & & & & & & &
\end{tabular}


Table 8. Normalized response, grey relational coefficients and grey relational grade for the segmented micro-channel.

\begin{tabular}{rcccccccc}
\hline & \multicolumn{3}{l}{ Normalized response } & \multicolumn{3}{c}{ GRC } & \multirow{2}{*}{ GRG } & Orders \\
\cline { 2 - 7 } Runs & SP & PD & TV & SP & PD & TV & & \\
\hline 1 & 0.476 & 0.751 & 0.910 & 0.488 & 0.668 & 0.847 & 0.686 & 9 \\
2 & 0.778 & 0.790 & 0.937 & 0.693 & 0.704 & 0.888 & 0.774 & 3 \\
3 & 0.191 & 0.853 & 0.827 & 0.382 & 0.773 & 0.743 & 0.644 & 13 \\
4 & 0.403 & 0.740 & 0.855 & 0.456 & 0.658 & 0.776 & 0.644 & 12 \\
5 & 0.740 & 0.723 & 0.340 & 0.658 & 0.643 & 0.431 & 0.563 & 18 \\
6 & 0.189 & 0.724 & 0.000 & 0.381 & 0.644 & 0.333 & 0.441 & 26 \\
7 & 0.382 & 0.676 & 0.244 & 0.447 & 0.607 & 0.398 & 0.476 & 25 \\
8 & 0.591 & 0.472 & 0.408 & 0.550 & 0.487 & 0.458 & 0.494 & 24 \\
9 & 0.413 & 0.356 & 0.263 & 0.460 & 0.437 & 0.404 & 0.431 & 27 \\
10 & 0.311 & 0.897 & 0.410 & 0.420 & 0.829 & 0.459 & 0.558 & 19 \\
11 & 0.350 & 0.890 & 0.242 & 0.435 & 0.820 & 0.397 & 0.535 & 21 \\
12 & 1.000 & 0.000 & 0.778 & 1.000 & 0.333 & 0.693 & 0.677 & 10 \\
13 & 0.972 & 0.846 & 1.000 & 0.947 & 0.764 & 1.000 & 0.913 & 1 \\
14 & 0.618 & 0.924 & 0.585 & 0.567 & 0.868 & 0.546 & 0.649 & 11 \\
15 & 0.860 & 0.543 & 0.893 & 0.781 & 0.523 & 0.823 & 0.720 & 6 \\
16 & 0.877 & 0.813 & 0.621 & 0.802 & 0.727 & 0.569 & 0.686 & 8 \\
17 & 0.296 & 0.886 & 0.165 & 0.415 & 0.815 & 0.374 & 0.519 & 23 \\
18 & 0.821 & 0.225 & 0.477 & 0.737 & 0.392 & 0.489 & 0.534 & 22 \\
19 & 0.043 & 0.974 & 0.611 & 0.343 & 0.951 & 0.563 & 0.613 & 15 \\
20 & 0.618 & 0.851 & 0.393 & 0.567 & 0.771 & 0.452 & 0.582 & 17 \\
21 & 0.499 & 0.899 & 0.034 & 0.500 & 0.832 & 0.341 & 0.536 & 20 \\
22 & 0.000 & 1.000 & 0.432 & 0.333 & 1.000 & 0.468 & 0.587 & 16 \\
23 & 0.758 & 0.928 & 0.814 & 0.674 & 0.874 & 0.729 & 0.756 & 4 \\
24 & 0.775 & 0.909 & 0.681 & 0.690 & 0.847 & 0.610 & 0.705 & 7 \\
25 & 0.259 & 0.953 & 0.975 & 0.403 & 0.915 & 0.952 & 0.776 & 2 \\
26 & 0.820 & 0.756 & 0.897 & 0.735 & 0.672 & 0.830 & 0.754 & 5 \\
27 & 0.694 & 0.836 & 0.564 & 0.620 & 0.753 & 0.534 & 0.626 & 14 \\
\hline & & & & & & & & \\
& & & & \\
12 &
\end{tabular}




\section{Figure Captions}

Fig. 1(a). Straight-channel design. (b). Novel segmented micro-channel design. (c). Schematic diagram of the segmented micro-channel design.

Fig. 2 Structured mesh of the micro-channel.

Fig. 3. Thermal performance of the straight-channel for different mass flow rates of water.

Fig. 4. Temperature contour plot of the straight-channel at $100 \mathrm{gs}^{-1}$.

Fig. 5. Pumping power consumption for the straight-channel for different mass flow rates of water.

Fig. 6. Comparison of the Nusselt number result with literature correlations.

Fig. 7. Comparison of the friction factor with literature correlations.

Fig. 8. The effects of design parameters on the specific performance.

Fig. 9. The effects of design parameters on the pressure drop.

Fig. 10. The effects of design parameters on the temperature variation.

Fig. 11. The contribution ratio of design parameters to specific performance, pressure drop and temperature uniformity.

Fig. 12. Average Grey relational grade for combination of all responses.

Fig. 13. Thermal performance of the segmented micro-channel for different mass flow rates of water.

Fig. 14. Temperature contour plot of the segmented micro-channel at $15 \mathrm{gs}^{-1}$.

Fig. 15. Pumping power consumption for the segmented micro-channel for different mass flow rates of water.

Fig. 16. Comparison of straight-channel and segmented micro-channel heat sinks thermal resistance.

Fig. 17. Comparison of straight-channel and segmented micro-channel heat sinks variation of temperature.

Fig. 18. Comparison of straight-channel and segmented micro-channel heat sinks pressure drop. 
Fig.1

(a)

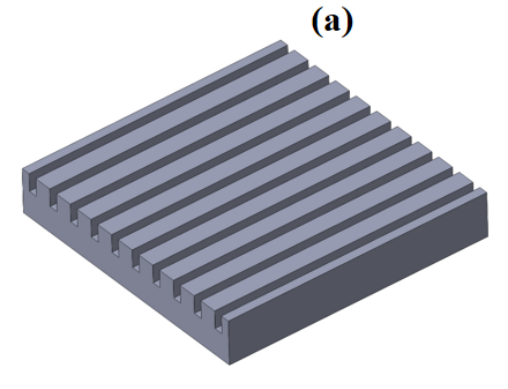

(b)

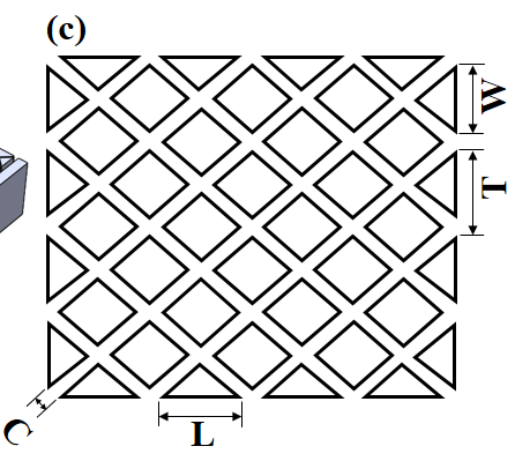

Fig.2

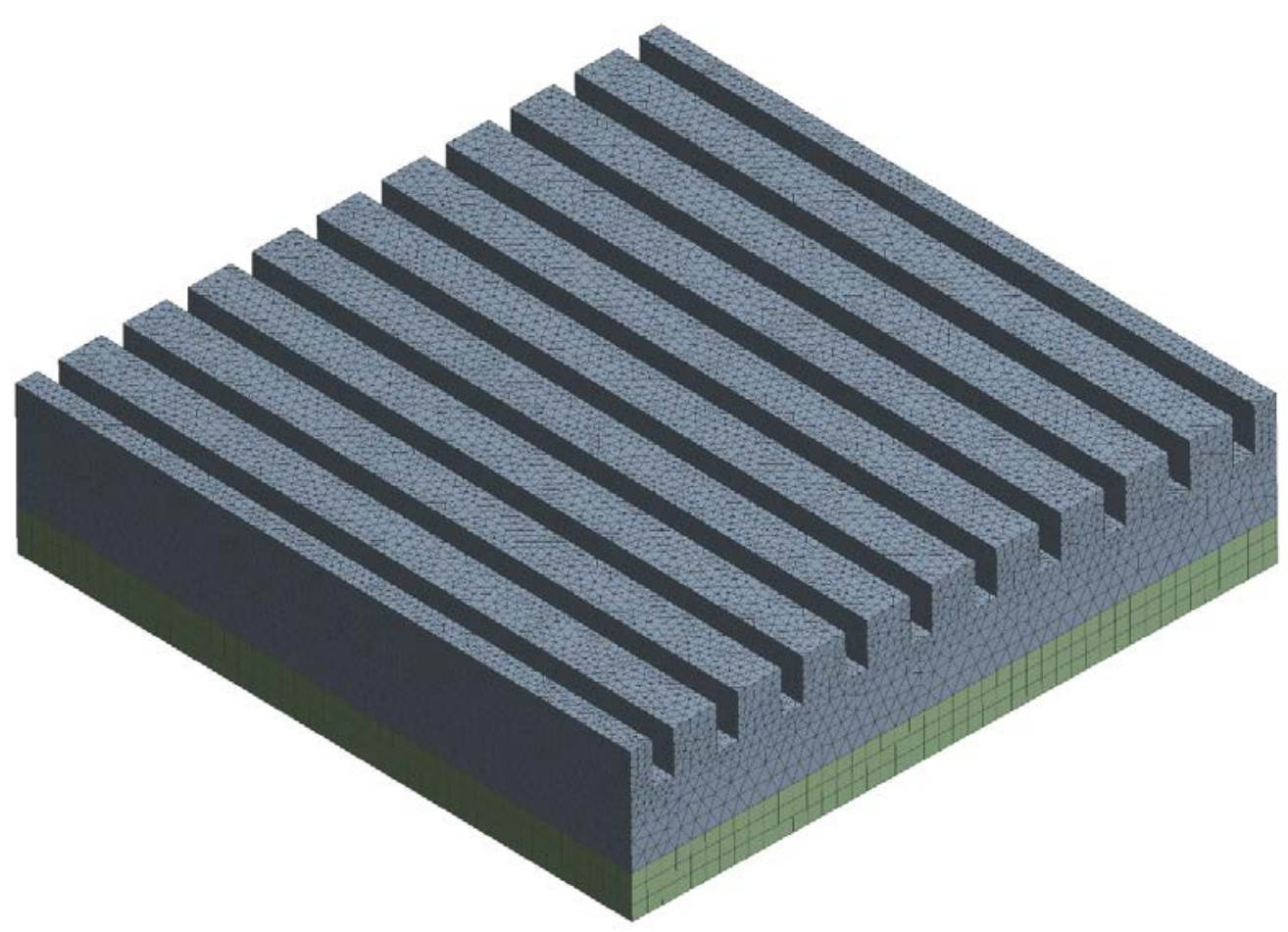


Fig.3

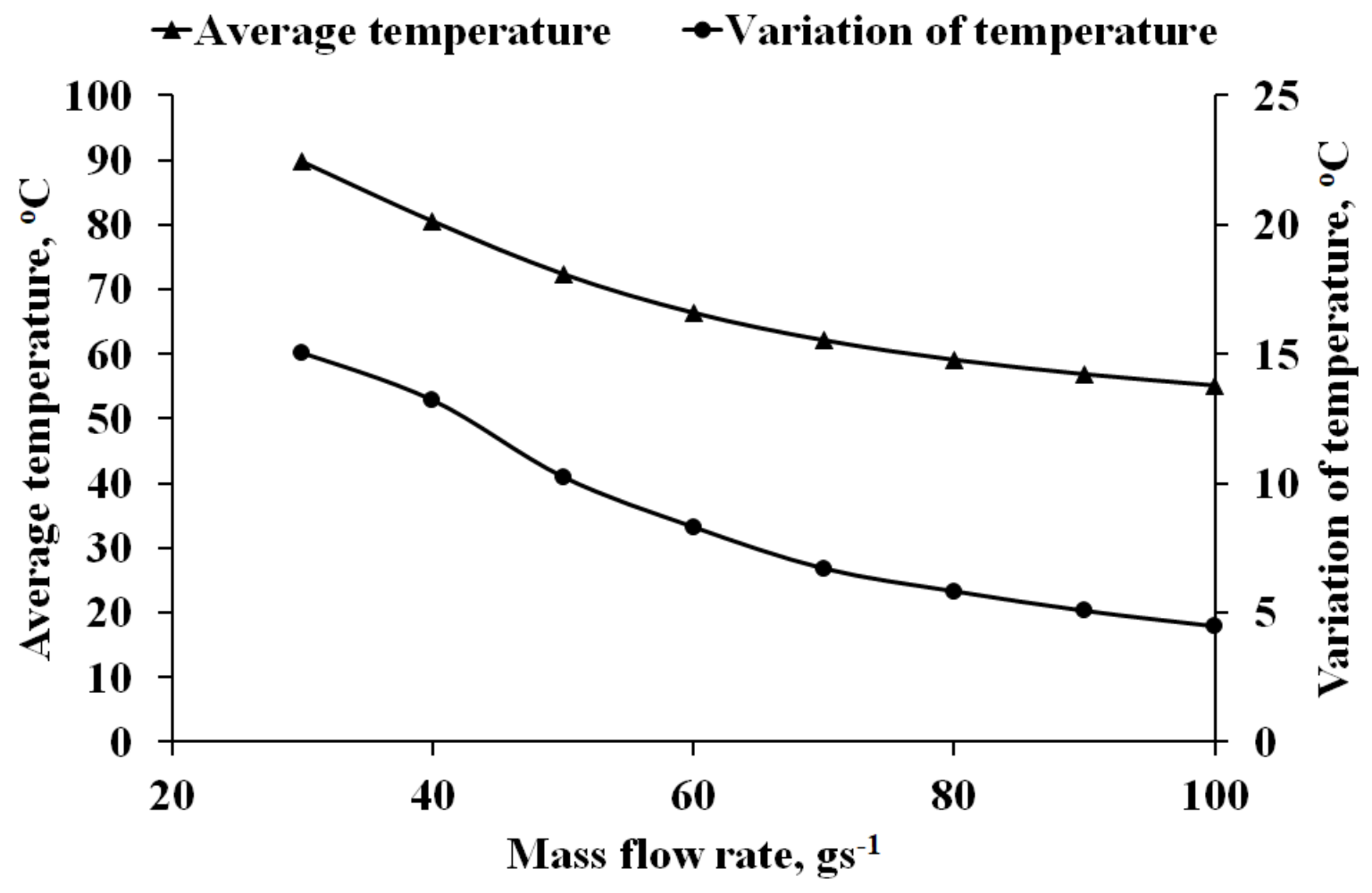

Fig.4

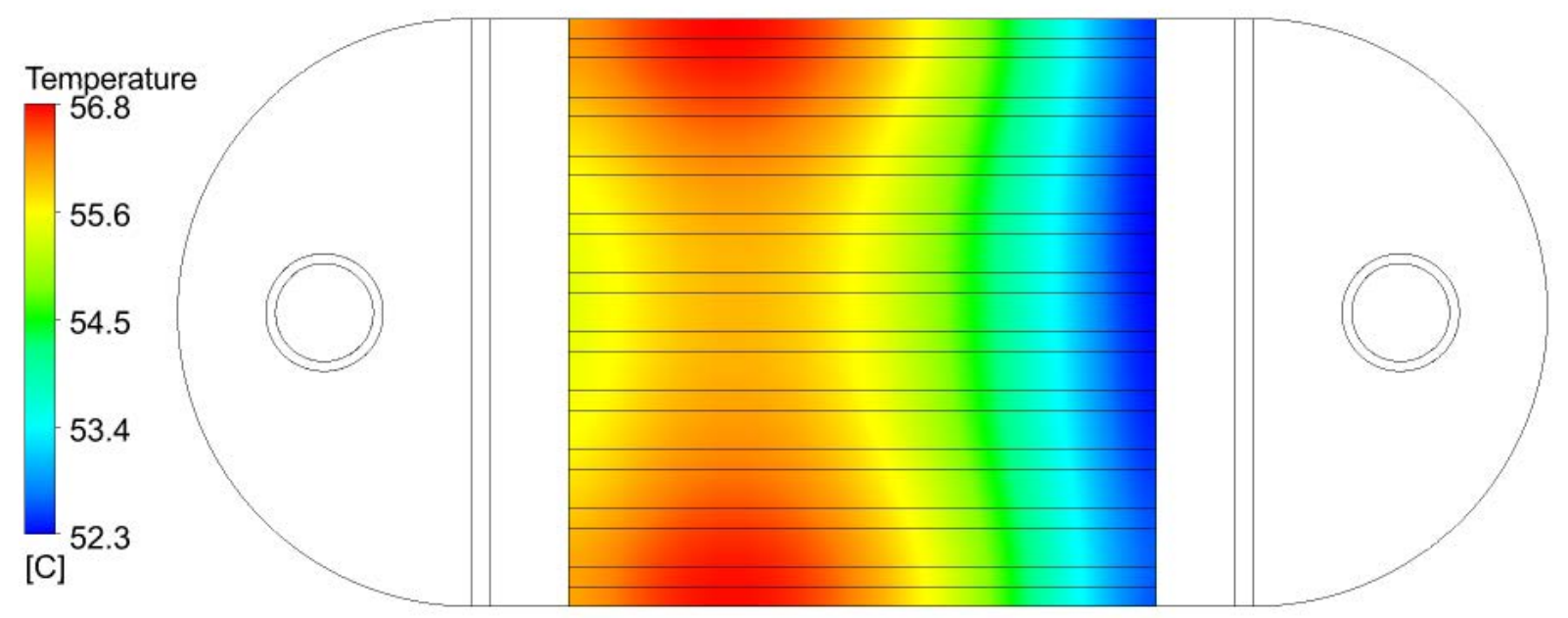


Fig.5

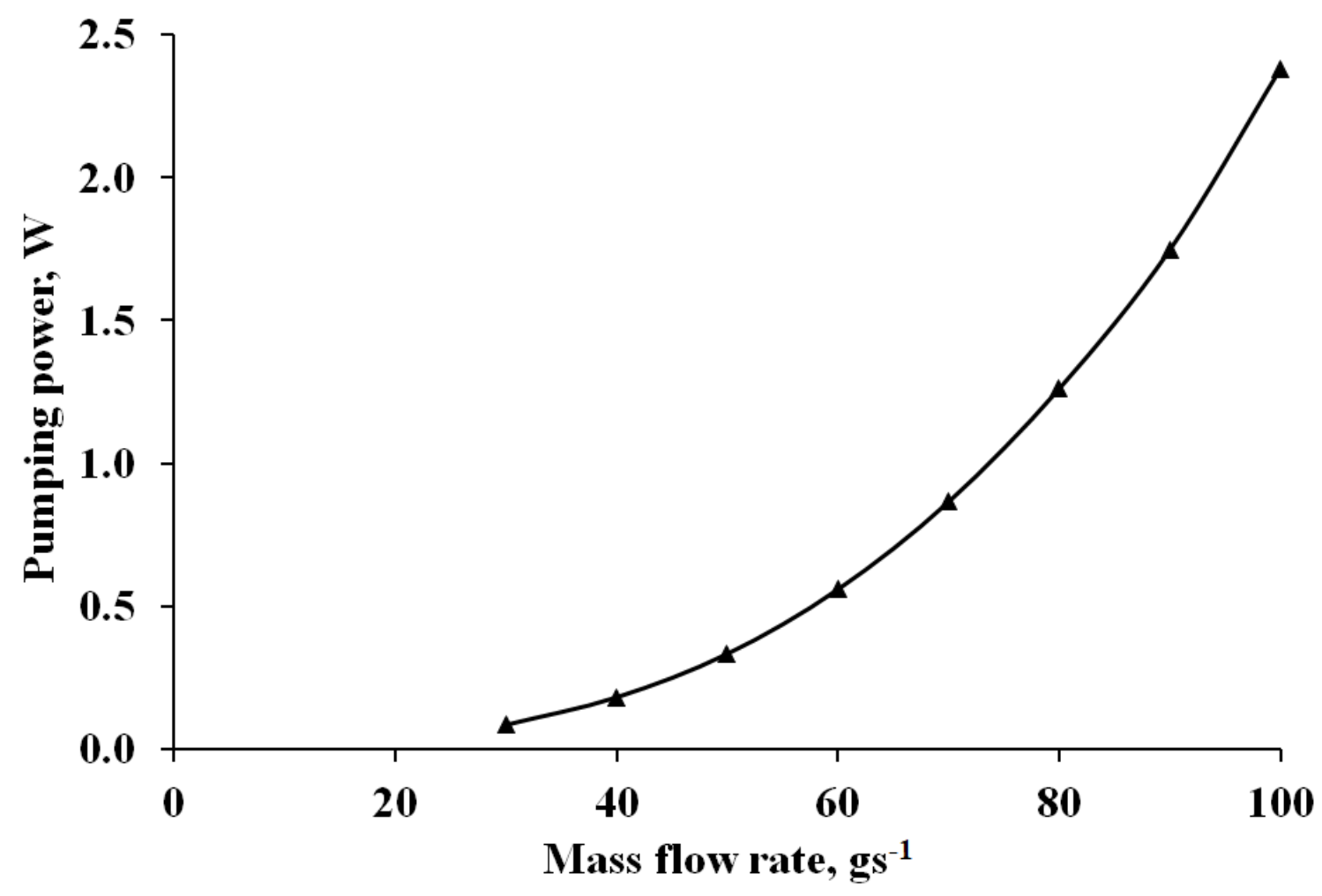

Fig.6

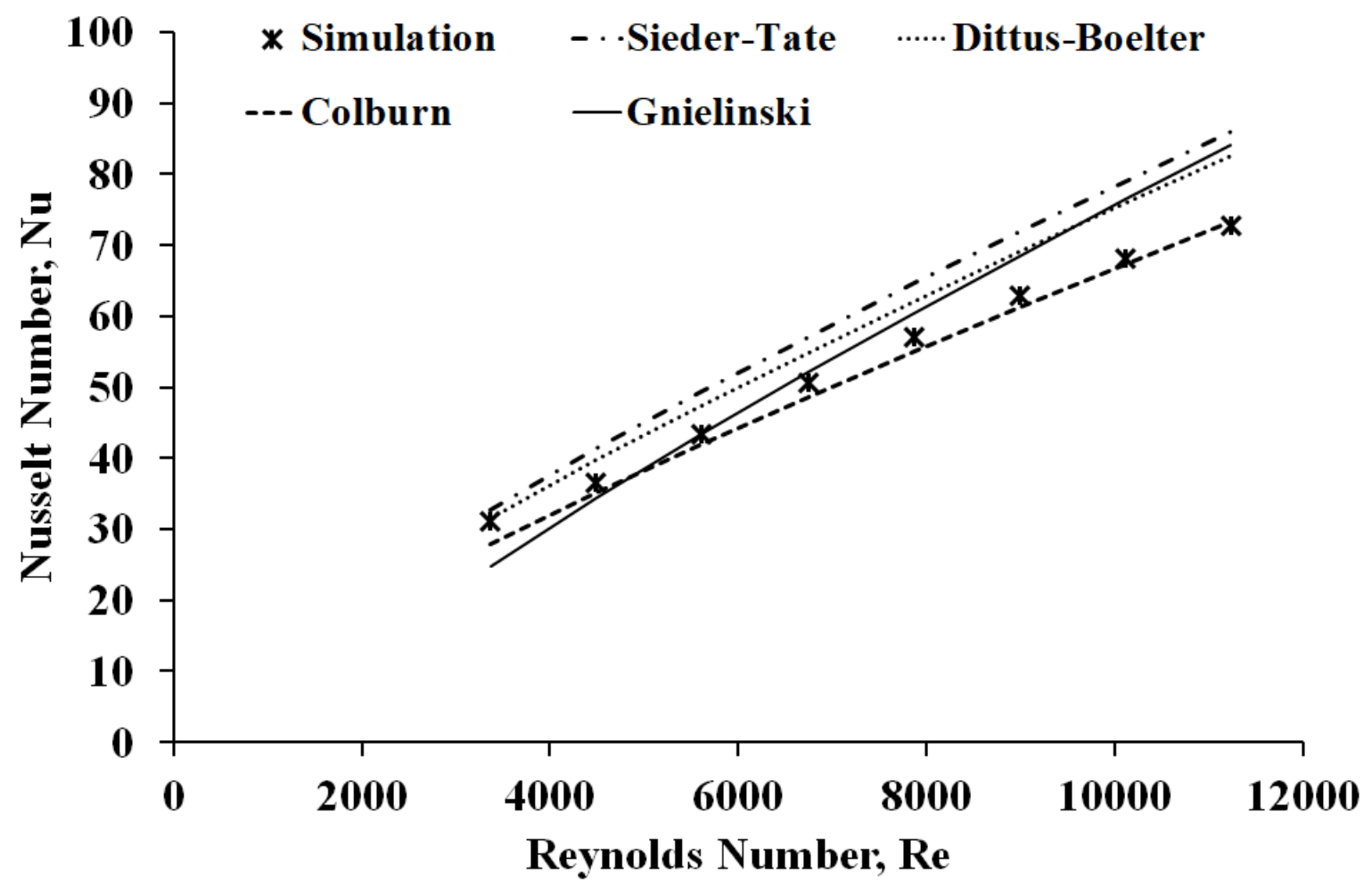


Fig.7

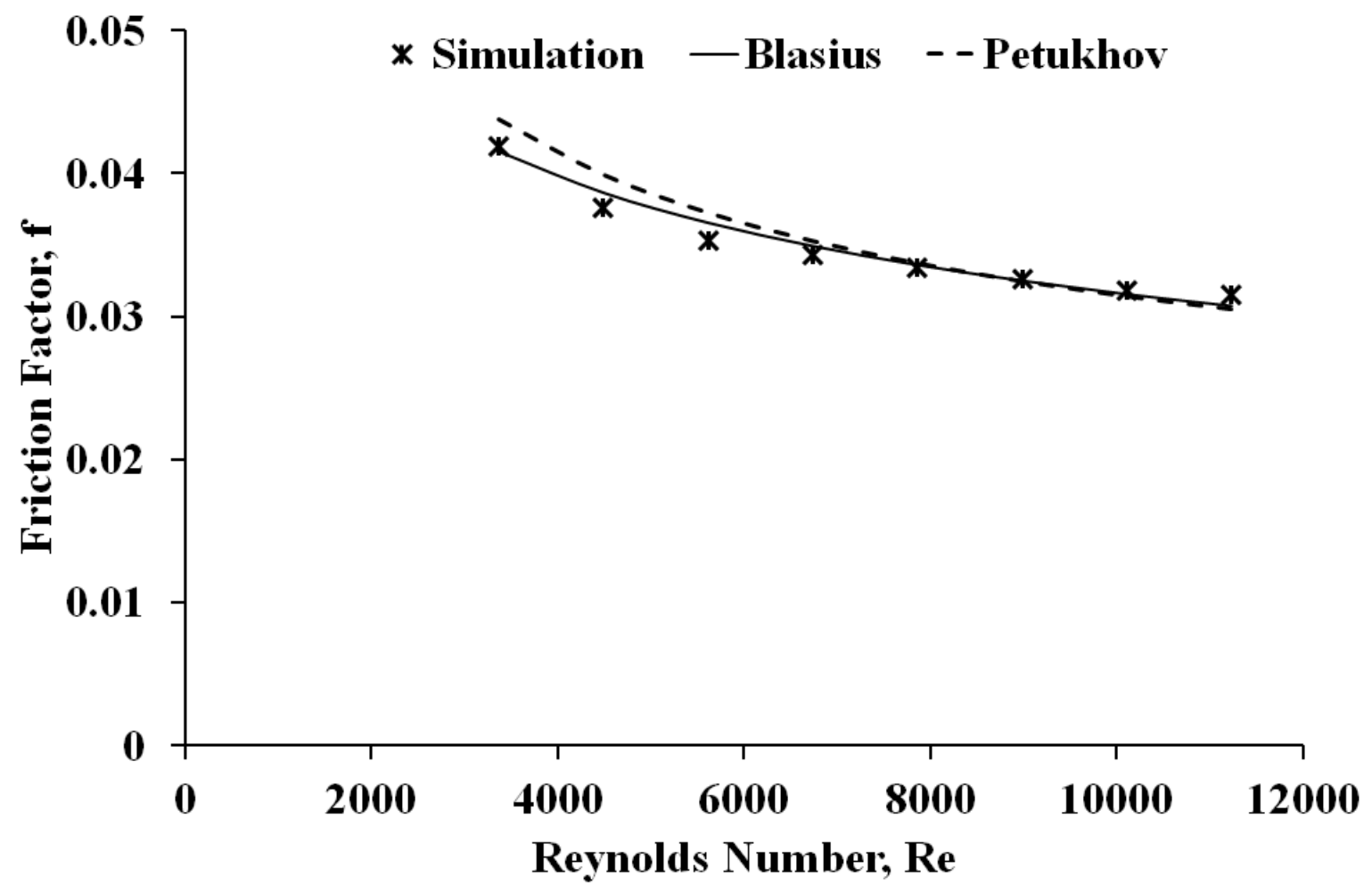

Fig 8

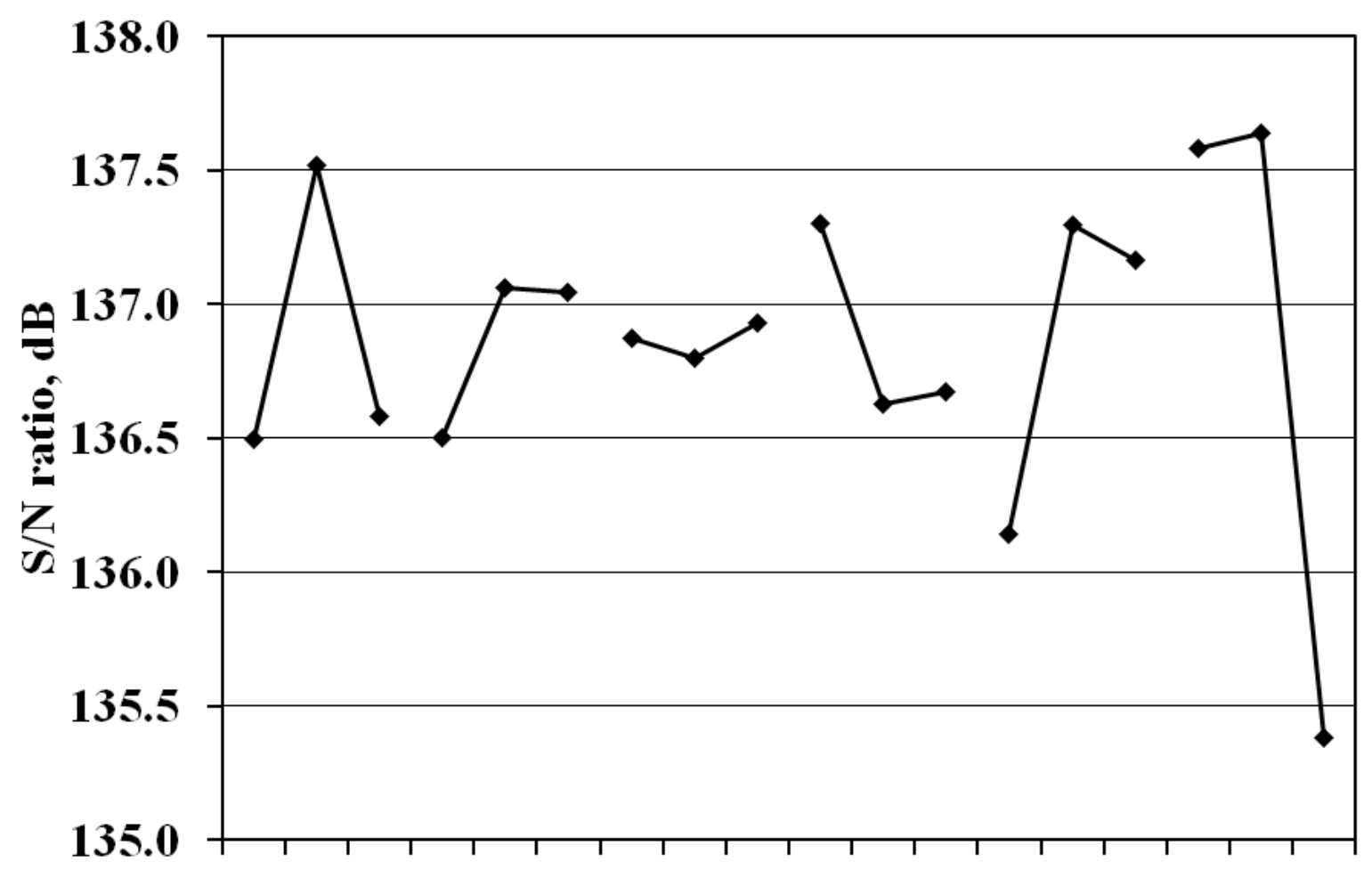

A1 A2 A3 B1 B2 B3 C1 C2 C3 D1 D2 D3 E1 E2 E3 F1 F2 F3

Design parameter 
Fig.9

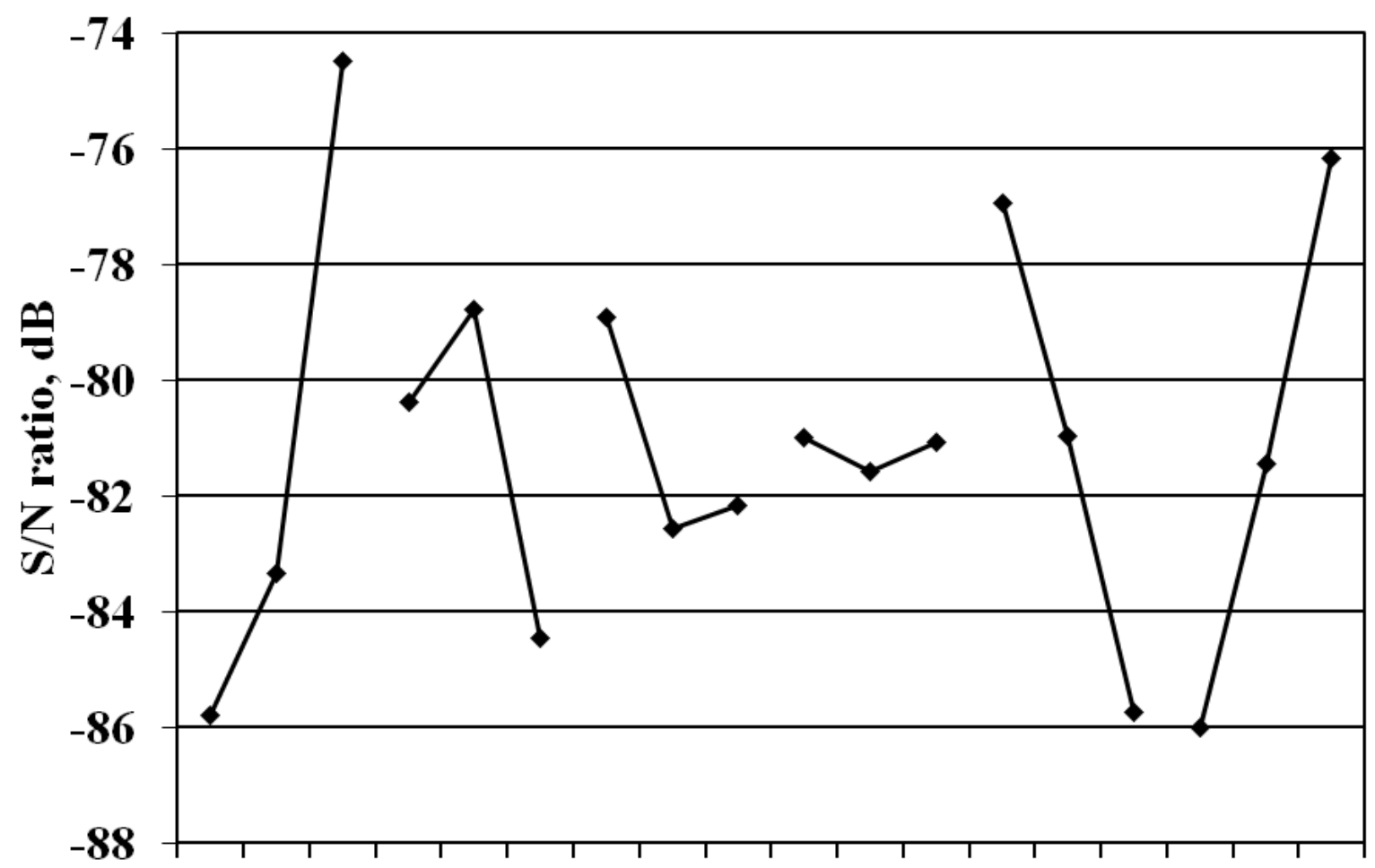

A1 A2 A3 B1 B2 B3 C1 C2 C3 D1 D2 D3 E1 E2 E3 F1 F2 F3 Design parameter

Fig.10

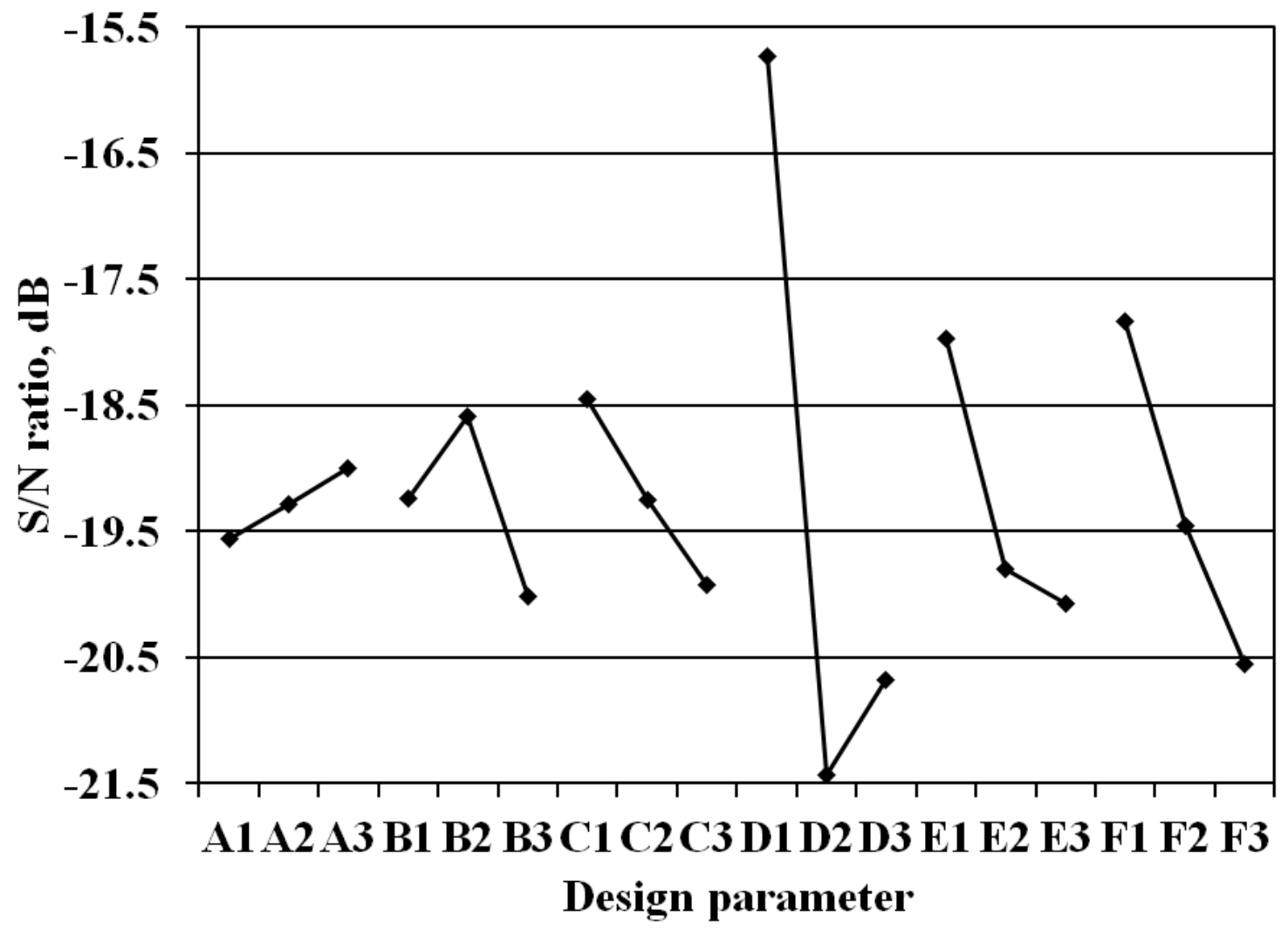


Fig. 11

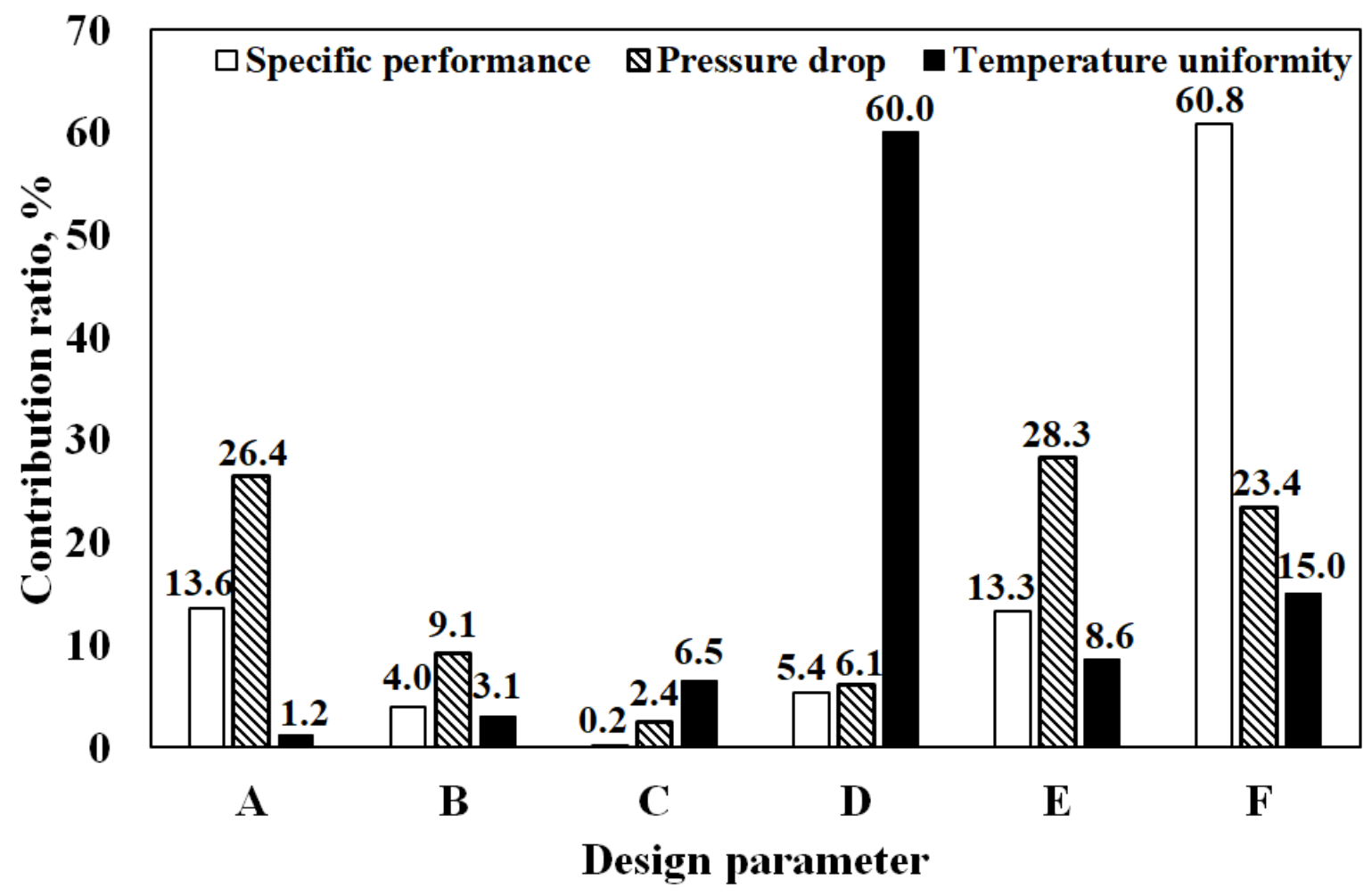

Fig.12

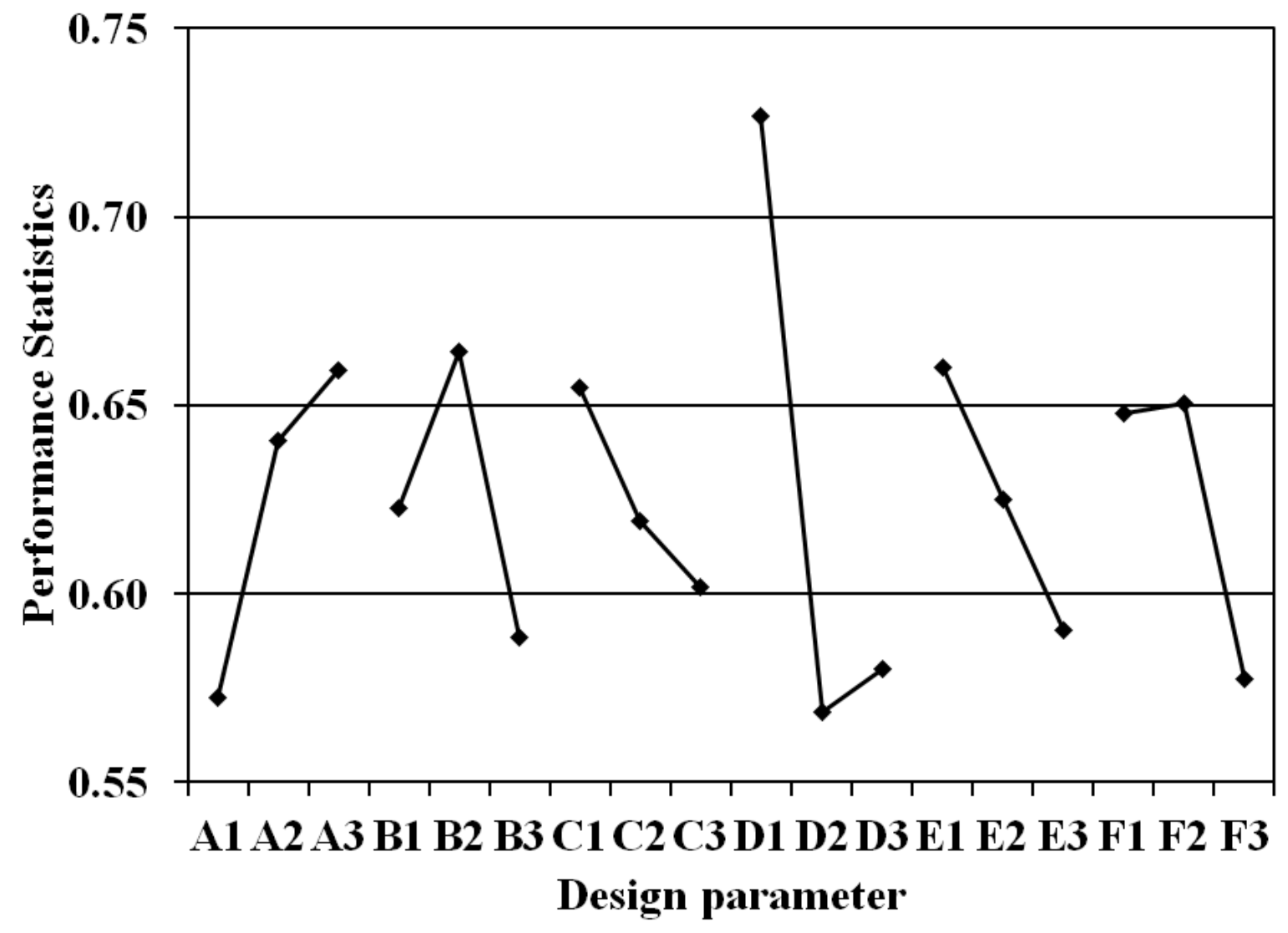


Fig.13

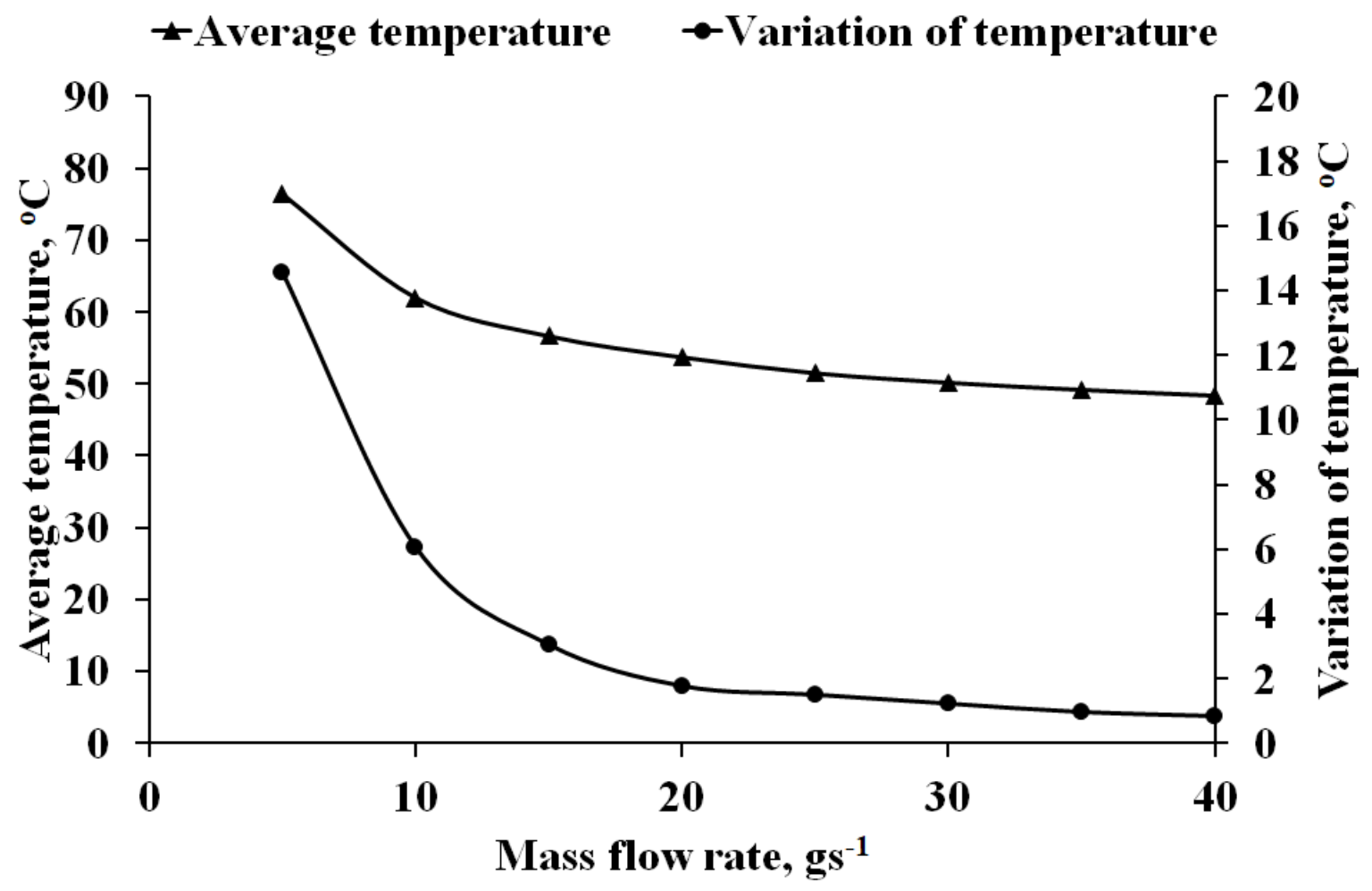

Fig 14

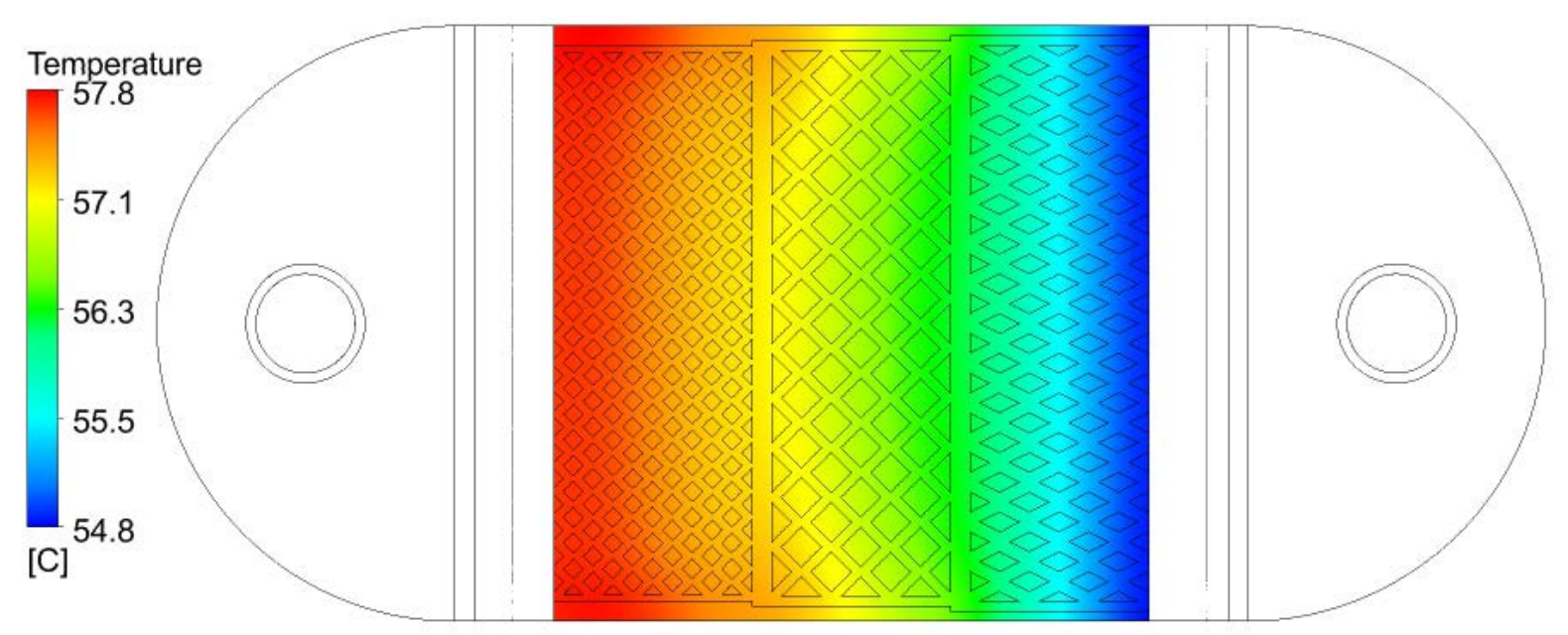


Fig.15

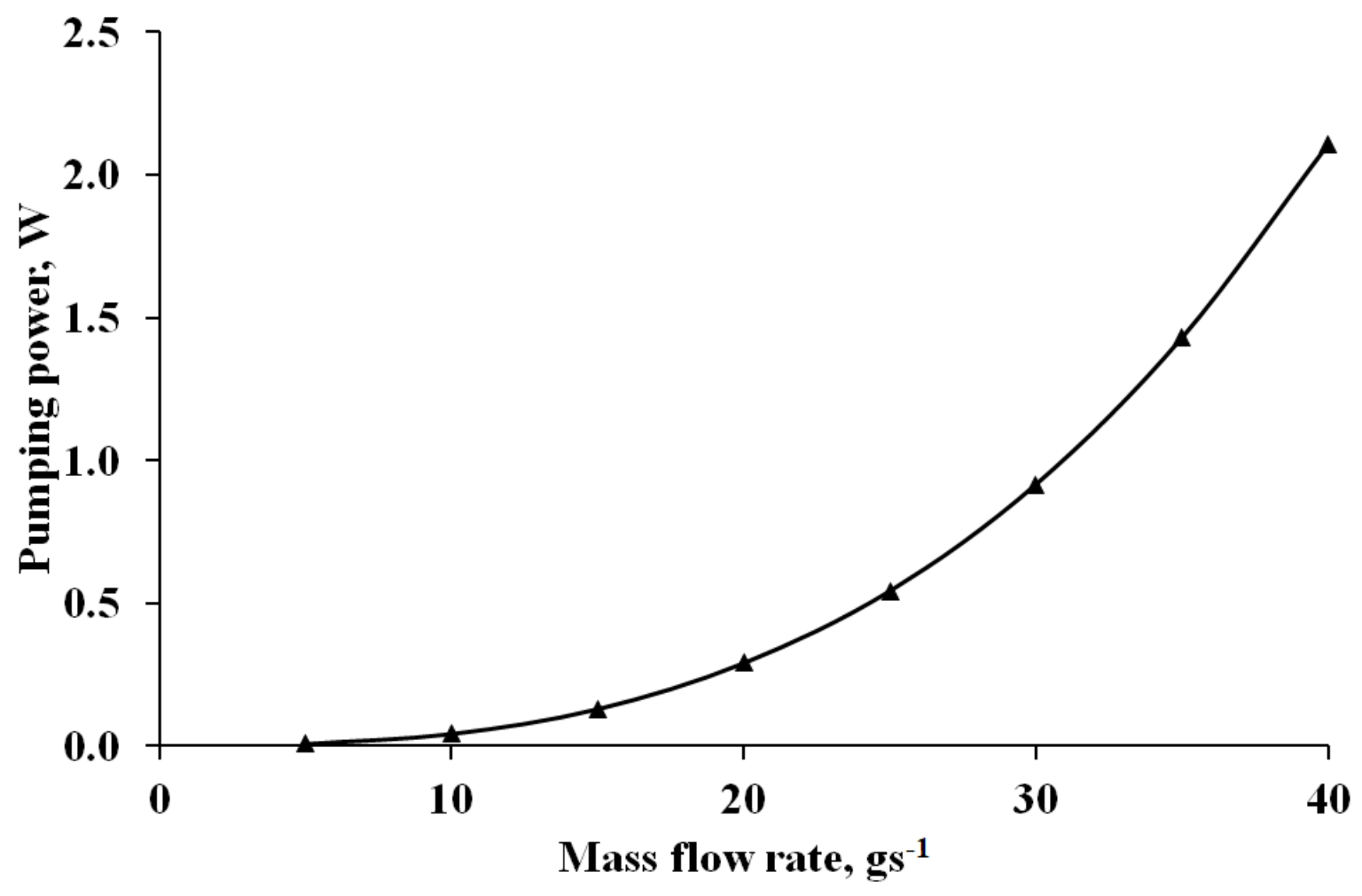

Fig 16

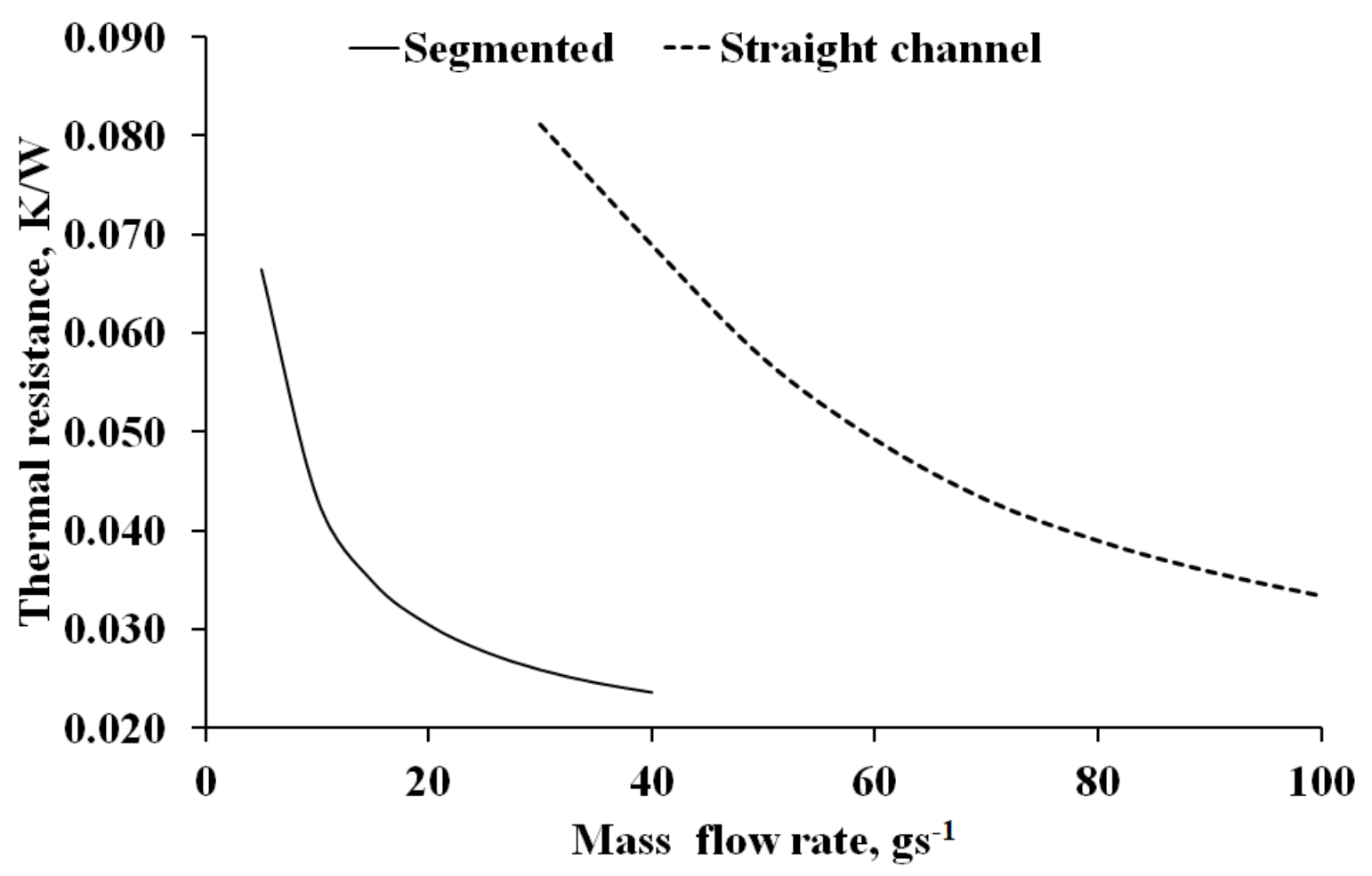


Fig. 17

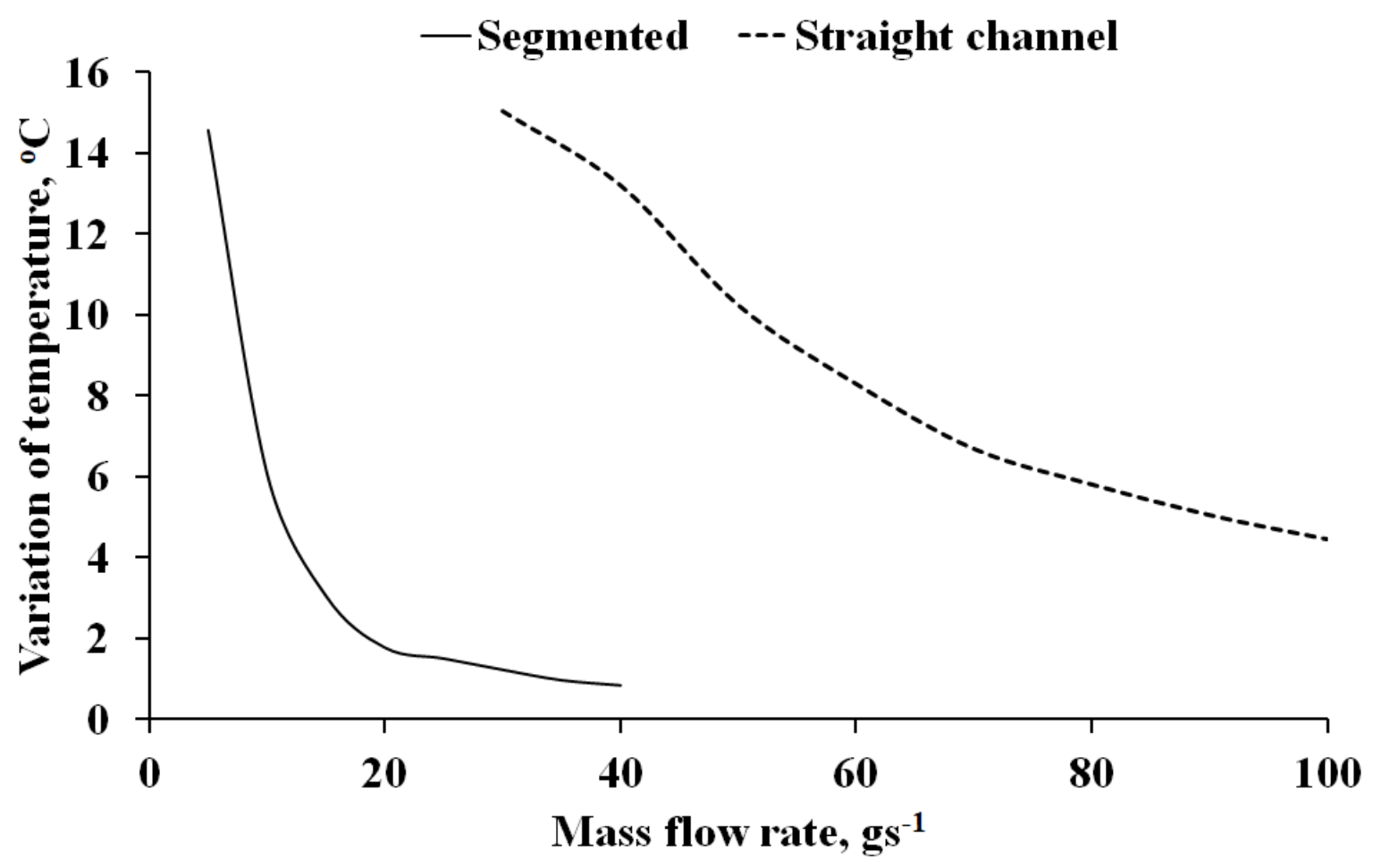

Fig.18

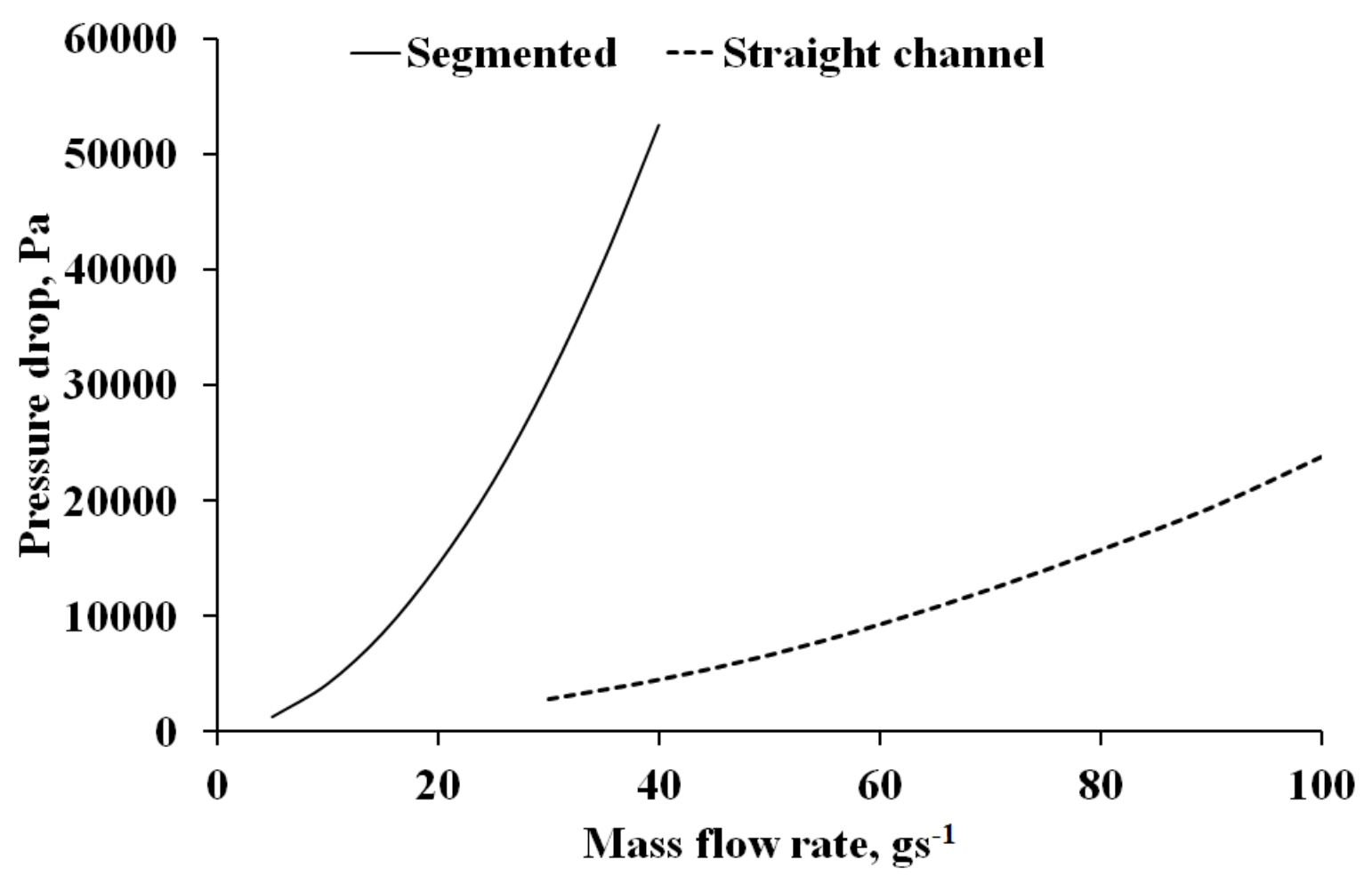

